\title{
UNIVERSITY OF VIRGINIA
}

\author{
Mechanical \& Aerospace Engineering
}

\section{Experimental Investigation of Soot Particle Size Evolution in Micro-Flow Tube Reactor}

Author:

Shawali CHAudhury
Supervisor:

Dr. Harsha Chelliah

\begin{abstract}
A thesis submitted in partial fulfillment of the requirements for the degree of Master of Science in Mechanical and Aerospace Engineering

School of Engineering and Applied Science
\end{abstract}

May 2016 


\begin{abstract}
The acute health and environment effects of soot emissions are well recognized. Most importantly, soot particulate matters have been strongly associated with pulmonary and cardiovascular diseases due to their small size $(<2.5 \mu \mathrm{m})$. Wide spread experimental and computational efforts are ongoing in an attempt to gain deeper understanding of soot formation processes. However, information about soot formation mechanisms in practical combustion conditions remains limited, especially under conditions of elevated pressures and relatively low temperatures (around $1200 \mathrm{~K}$ ). Moreover, previously proposed principles of soot nucleation and growth need experimental evidence for their firm establishment. In fact, validation of predictive models of soot formation requires reliable experimental data that the model prediction can be tested against.
\end{abstract}

In light of these requirements in combustion and soot research, the present study undertakes an experimental investigation of soot formation from fuel pyrolysis in a micro-flow tube reactor. Soot formation is monitored by tracking the evolution of particle size distributions under different experimental conditions using a high resolution Scanning Mobility Particle Sizer comprising of TSI 3080 nano-DMA and TSI 3788 nano-Water based CPC. An analysis of soot particle size distributions so obtained provides critical information about the various processes involved in soot formation.

The objectives of this study are mainly two fold. The first objective of this study to to obtain experimental training data set for soot formation under elevated pressure conditions. The second objective of this study is to experimentally verify the role of acetylene in soot formation, particularly the importance of hydrogen abstraction/carbon addition (HACA) mechanism in soot surface growths. Accordingly, the first part studies soot formation during the pyrolysis of $2 \%$ ethylene in $98 \%$ inert $N_{2}$ bath at $1200 \mathrm{~K}$ under elevated pressure conditions (2.5 atm - $2.8 \mathrm{~atm}$ ) in a novel micro-flow tube reactor with $231 \mu \mathrm{m}$ orifice (corresponding to $240 \mathrm{~ms}$ residence time) at the reactor exit. The orifice allows choked flow conditions, and hence allows us to realize constant elevated pressure conditions. Analysis of soot formation over this range of pressures showed that increasing pressures resulted in an apparent increase in the density of soot precursor, which is evident from the increase in total soot number density (this indicates the formation of more soot nuclei). As a consequence of strengthened soot nucleation rates, soot mean particle size undergoes a noticeable increase.

The second part of this study examines the effect of acetylene on soot formation during ethylene pyrolysis. Hence this study aims to identify the role of acetylene as a soot precursor, as well as validate the well-known hydrogen-abstraction/carbon-addition (HACA) mechanism for soot growth. These experiments involve the pyrolysis of ethylene doped with small amount of acetylene in a micro-flow straight tube reactor at different temperatures $(1210 \mathrm{~K}-1230 \mathrm{~K})$ and residence times $(215 \mathrm{~ms}-315$ $m s)$. The molar ratio of ethylene/acetylene was maintained at 6 . The reactant composition was $4 \%$ fuel mix in $96 \% N_{2}$ bath. Soot particle size distributions were compared with those obtained from baseline ethylene pyrolysis ( $4 \%$ pure ethylene in $96 \% N_{2}$ bath). Soot number density, mean diameter and total volume fraction showed a significant increase as a result of acetylene doping. The results clearly demonstrate the crucial role of acetylene in soot inception as well as soot growth resulting 
in an increase in soot sizes. This correlation between acetylene doping and formation of more soot nuclei (evinced by the higher number density), and larger soot particles (as proved by larger mean diameter and higher soot volume fraction) lends credence to the assessment that acetylene is an important soot precursor, and HACA mechanism is the dominant soot growth pathway.

This study is a valuable preliminary work towards the establishment of a consistent and experimentally verified soot formation theory. 


\section{Acknowledgements}

I would like to express my sincere gratitude to my advisor, Dr. Harsha Chelliah for allowing me with this opportunity and for his guidance in the course of this research.

I am grateful to Dr. Chowdhury Moniruzzaman for his help in providing me with the tools for effective analysis of my experimental results. I also want to thank all my colleagues in the lab, especially Rohit Singhal for guiding me in the proper use of the lab instrumentation for successful experimental investigation.

Lastly, I would like to thank my family for their invaluable support. 


\section{Contents}

\begin{tabular}{lll}
\hline Abstract & i
\end{tabular}

Symbols viii

$\begin{array}{lll}1 & \text { Introduction } & 1\end{array}$

1.1 Literature Review . . . . . . . . . . . . . . . . . . . . . . . . . 2

1.1 .1 Experimental Studies . . . . . . . . . . . . . . . . . . 2

1.1 .2 Modeling Studies . . . . . . . . . . . . . . . . . . 5

$\begin{array}{llr}2 & \text { Motivation } & 8\end{array}$

$2.1 \quad$ Effect of Pressure . . . . . . . . . . . . . . . . . . . . . . . . . . . . . . . . . 8

2.2 Effect of Acetylene on Soot formation during Ethylene Pyrolysis $\ldots \ldots \ldots$

\begin{tabular}{lll}
\hline 3 & Experimental Set-Up & 11
\end{tabular}

$3.1 \quad$ Atmospheric Pressure Reactor . . . . . . . . . . . . . . . . . . . . . . . . . 11

3.2 Elevated Pressure Reactor . . . . . . . . . . . . . . . . . . . . . . . . . . . . . . . 13

3.3 Sampling Probe Design and Dilution $\ldots \ldots \ldots \ldots$. . . . . . . . . . . . 13

3.4 Scanning Mobility Particle Sizer $\ldots \ldots \ldots \ldots$. . . . . . . . . . . . . 15

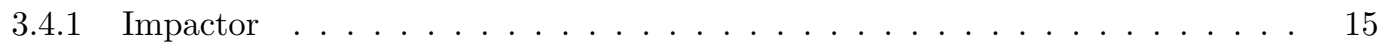

$3.4 .2 \quad$ Electrostatic classifier . . . . . . . . . . . . . . . . . . 16

3.4 .3 Nano-Water Bases Condensation Particle Counter . . . . . . . . . . . . . . . 17

3.4 .4 Mobility Diameter . . . . . . . . . . . . . . . . . . . . . 18

3.5 Calibration of Orifice Flow Rate $\ldots \ldots \ldots \ldots$

3.6 Plug Flow Assumption $\ldots \ldots \ldots \ldots \ldots$. . . . . . . . . . . . . . . . . . . . . 21

3.7 Heat Transfer and Temperature Ramp-Up Section . . . . . . . . . . . . . . . . . . . 21

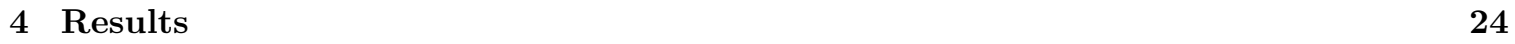

4.1 Dilution Effects . . . . . . . . . . . . . . . . . . . . . . . . . . . . . . . . . . . . . 24

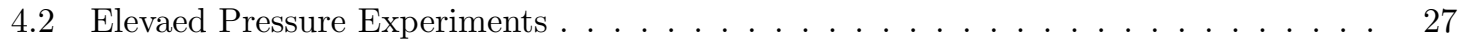

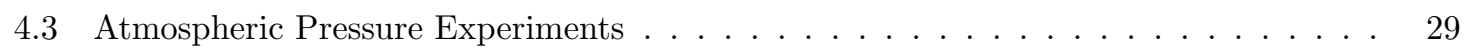

4.3 .1 Pyrolysis of Fuel-Mix $\ldots \ldots \ldots \ldots$

$4.3 .2 \quad$ Absolute Particle Size Distributions for Baseline Ethylene Pyrolysis . . . . . 33

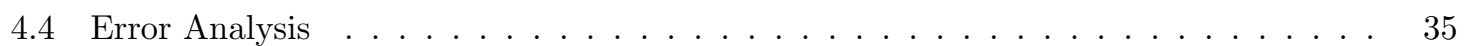


4.5 Summary $\ldots \ldots \ldots \ldots \ldots \ldots \ldots$

$\begin{array}{lll}5 & \text { Conclusion } & 40\end{array}$

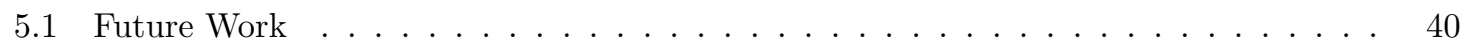




\section{List of Tables}

4.1 Elevated Pressure Experimental Conditions $\ldots \ldots \ldots \ldots \ldots \ldots \ldots$

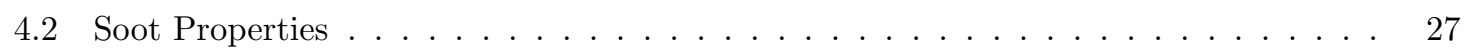

4.3 Experimental Cases \& Properties of Soot obtained from $\mathrm{C}_{2} \mathrm{H}_{2}$-doped $\mathrm{C}_{2} \mathrm{H}_{4}$ Pyrolysis 29

4.4 Experimental Conditions for Pure $4 \%$ Ethylene Pyrolysis $\ldots \ldots \ldots$. . . . . . . . . . . . . . . . . . 33

4.5 Comparison of Soot PSD Properties $\ldots \ldots \ldots \ldots \ldots \ldots$ 


\section{List of Figures}

1.1 Steps involved in soot formation $[1] \ldots \ldots \ldots \ldots \ldots$

3.1 Schematic of experiment set-up for micro-flow atmospheric tube reactor (MFTR) . . 12

3.2 Comparison of Particle Size Distribution of Ambient Air and Pure Nitrogen . . . . . 14

3.3 Cross-Sectional view of Inertial Impactor [2] . . . . . . . . . . . . . . . . . . . . 15

3.4 Flow schematic for the TSI 3080 Electrostatic Classifier with nano-DMA in dual-

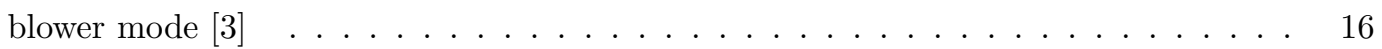

$3.5 \quad$ Flow schematic for the nano-CPC $[4] \ldots \ldots \ldots \ldots \ldots$

3.6 Relationship between Mobility Diameter and True Particle Diameter [5] . . . . . . . 18

3.7 Experimental Flow rate through orifice versus differential pressure across orifice for

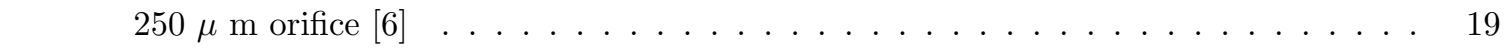

3.8 Variation of entrance length of flow through orifice as a function of pressure across

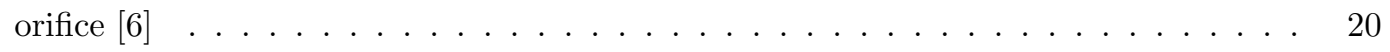

3.9 Numerical Solution of Temperature Profile under Nitrogen Flow . . . . . . . . . . 22

$4.1 \quad$ Range of Dilution-Ratios for Diluent $N_{2}$ flow rates $\ldots \ldots \ldots \ldots \ldots \ldots$

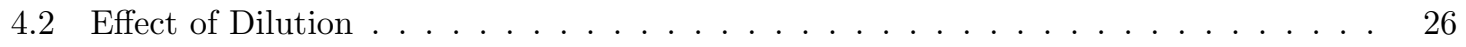

4.3 Comparison of Absolute Soot Particle Size Distribution and Soot Volume Fraction

Distribution at Different Pressures . . . . . . . . . . . . . . . . . 28

4.4 Absolute Soot PSDs as a Function of Residence Times for $\mathrm{C}_{2} \mathrm{H}_{2}$ - doped $\mathrm{C}_{2} \mathrm{H}_{4}$ py-

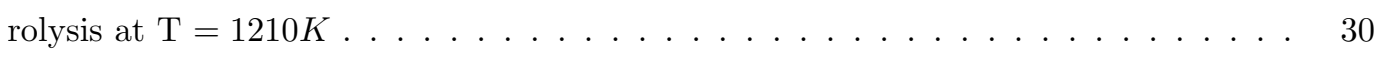

4.5 Absolute Soot PSDs as a Function of Residence Times for $\mathrm{C}_{2} \mathrm{H}_{2}$ - doped $\mathrm{C}_{2} \mathrm{H}_{4}$ py-

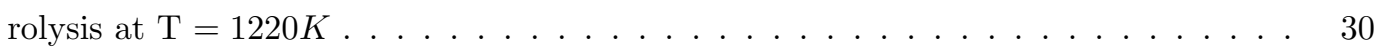

4.6 Absolute Soot PSDs as a Function of Residence Times for $\mathrm{C}_{2} \mathrm{H}_{2}-$ doped $\mathrm{C}_{2} \mathrm{H}_{4}$ py-

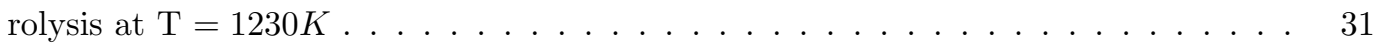

4.7 Effect of Temperature on Soot PSD for $\mathrm{C}_{2} \mathrm{H}_{2}-\operatorname{doped} \mathrm{C}_{2} \mathrm{H}_{4}$ pyrolysis at $280 \mathrm{~ms}$ Residence Time . . . . . . . . . . . . . . . . . . . . . . . . 32

4.8 Comparison of Absolute PSD of Baseline $\mathrm{C}_{2} \mathrm{H}_{4}$ with Absolute PSD of $\mathrm{C}_{2} \mathrm{H}_{2}$ - doped $\mathrm{C}_{2} \mathrm{H}_{4}$ (referred to as fuel mix) at $\mathrm{T}=1220 K \ldots \ldots \ldots 34$

4.9 Comparison of Absolute PSD of Baseline $\mathrm{C}_{2} \mathrm{H}_{4}$ with Absolute PSD of $\mathrm{C}_{2} \mathrm{H}_{2}$ - doped $\mathrm{C}_{2} \mathrm{H}_{4}$ (referred to as fuel mix) at $\mathrm{T}=1230 \mathrm{~K}$ and $280 \mathrm{~ms} \ldots \ldots \ldots 36$

4.10 Soot Particle Size Distribution with Error Bars $\ldots \ldots \ldots \ldots$. . . . . . . . . . . . . . . . . . . . . .

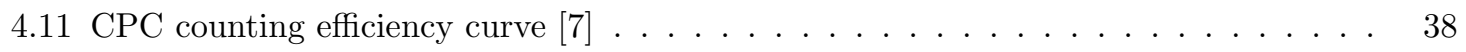




\section{Symbols}

A Area of cross-section of probe orifice

C Cunningham slip correction factor

$D_{\text {Kelvin }}$ Kelvin diameter

$D_{50} \quad$ Cut-point diameter at which particles are separated in Impactor

$D_{p} \quad$ True diameter obtained from mobility diameter measured by SMPS

$D_{p}^{\text {mobility }}$ Mobility diameter measured by SMPS

e Elementary charge $\left(1.6 \times 10^{? 19}\right.$ Coulomb $)$

$f_{D} \quad$ Dilution Ratio

$f_{w} \quad$ Factor to account for diffusive wall losses

$K_{n} \quad$ Knudsen Number

$N \quad$ Soot particle number density measured by SMPS

$N_{a} \quad$ Absolute number density of particles

$P \quad$ Pressure

$P_{s} \quad$ Saturation vapor pressure

$Q_{c} \quad$ Flow rate of carrier gas $N_{2}$ through the sampling probe

$Q_{o} \quad$ Flow rate through the orifice of the probe

T Temperature

$T_{r} \quad$ Ratio of inlet gas temperature and carrier gas temperature Specific volume

W Nozzle diameter of Impactor

Z $\quad$ Electrical mobility

$\Delta P \quad$ Pressure difference across the probe orifice

$\gamma \quad$ Surface tension 
$\begin{array}{ll}\Lambda & \text { Mean free path } \\ \mu & \text { Gas viscosity } \\ \rho & \text { Density } \\ \rho_{c} & \text { Density of condensing fluid in n-CWPC }\end{array}$ 


\section{Chapter 1}

\section{Introduction}

Soot formation and emission is a well-recognized problem associated with combustion processes. Combustion of hydrocarbon under stoichiometric conditions yields carbon dioxide and water vapor. Stoichiometric combustion is ideal because it is accompanied by maximum heat generation. However most practical combustion systems are characterized by local non-idealities. If the local oxygen concentration in a combustion system is less than stoichiometric amounts, then incomplete combustion takes place, which results in formation of molecules like carbon monoxides, hydrogen and other hydrocarbons and ultimately soot. Deposition of soot on combustion system severely affects its performance. This is especially problematic in regenerative cooling systems. In regenerative cooling methods, the endothermic process of thermally induced fuel cracking is used to reduce the heat load of combustion chamber walls. Under such pyrolytic conditions, a substantial amount of PAH (polycyclic aromatic hydrocarbon) and hence, soot is formed. Deposition of soot in the cooling channel inhibits efficient heat transfer. It may also cause problems downstream by clogging the injectors and obstruction the atomization process $[$, 9 .

Besides hindering the efficiency of combustion systems, soot formation results from the initial formation of certain classes of hydrocarbons (polycyclic aromatic hydrocarbons or PAH) that are known to have carcinogenic and mutagenic properties. It has been shown that these PAH not only contribute to the formation of soot, but also deposit on soot surfaces, thus traveling with soot particles. Soot is an especially dangerous pollutant because of its small size. Fine particulate matter is defined as any particle of aerodynamic diameter less than $2.5 \mu \mathrm{m}$. Studies have categorically established the relation between fine particulate matter (dominantly soot) and respiratory illness like asthma, bronchitis, reduced lung function, etc. In fact long term exposure to such particulate matter has been shown to cause lung cancer [8]. Additionally, soot particle size controls its residence time in the atmosphere. Particle sizes with aerodynamic diameter in the range of $0.1-10 \mu m$ have the longest residence times (up to a week) [9, thus increasing the exposure time to polycyclic aromatic hydrocarbons that have detrimental health effects. Environmental effects of soot particulate matter includes reduced visibility, which is affected by soot shape, size and morphology [10].

Clearly, size of soot particles is an important aspect with regards to environmental and health 
considerations. Moreover, it is agreed that information about soot size is crucial for development and validation of soot formation mechanism [11, 12, 13, which in turn is essential for designing effective soot abatement strategies. As a result, soot formation in combustion systems has been widely studied through experimental and computational means, over the past several decades.

\subsection{Literature Review}

Extensive experimental and computational studies have afforded a great deal of understanding about soot evolution and the associated mechanism. Due to the large body of available literature, the review has been conducted in two parts. The first part involves a review of the experimental studies while the second part discusses the advancement in computational modeling of soot formation.

\subsubsection{Experimental Studies}

There have been numerous experimental studies on soot formation in varied reactor configurations. The most common reactor configurations are burner stabilized flames (both diffusion flames and premixed flames) and shock wave tube reactor. The widespread use of burner stabilized laminar flames in laboratory studies may be attributed to the fact that they provide time invariant, laminar, 1-dimensional flow (radial uniformity is assumed in burner stabilized flames) that allow convenient diagnostics along the axis [14, 15, 16. However, flame stability becomes an issue under varied reaction conditions. Shockwave reactors are another commonly used experimental platform. Shock tubes are ideal adiabatic reactors that are suitable for maintaining nearly uniform operating conditions (temperature and pressure) and near plug flow conditions [17. Shock tubes offer the advantage of conducting parametric studies by maintaining precise operating conditions that can be separately controlled [18. Another incentive for obtaining training data from shock tube experiments lies in its clean boundary conditions that are amenable for numerical modeling. Shock tubes allow the instantaneous realization of high temperatures and pressures that characterize more practical combustion systems [19, 20. Consequently, one of the major limitations of shock tubes is the short residence times (of the order of milliseconds) of the reactions. It is crucial to point out that diffusion flames vary fundamentally from premixed flames. While diffusion flames are apt for simulating the rich pyrolysis region associated with soot generation, yet, unlike premixed flames and shock tube experiments that allow more easily controlled experiments, diffusion flames are inherently characterized by time variant reaction conditions like temperature [21]. Additionally, diffusion flames are different from shock tubes in that they have much longer residence times [21. Besides shock tube and flame studies, laminar flow reactors have recently gained popularity [22, 23, 6] as a standard set-up for combustion experiments and soot studies; and have been chosen as the reactor set up for the present investigation.

These experiments have routinely studied soot formation resulting from simpler aliphatics like methane, ethane, ethylene, propene and butene, as these are important intermediates formed during oxidation and pyrolysis of larger alkanes (that comprise jet fuel mixtures). Moreover, olefin intermediates are the key species involved in the eventual formation of soot precursors. In particular, soot 
formation during ethylene combustion has received wide attention due to its comparatively greater stability at high temperatures. The dominant soot investigation methods can be broadly classified into two categories. The first approach involves identifying chemical species formed during different reaction stages leading up to soot formation. The second strategy for studying soot focuses on determining soot properties. The motivation behind the first approach is to utilize measured species profile for predicting possible reaction pathways leading to soot formation. To this end, several experimental studies involving various fuels/fuel blends at different equivalence ratio, temperature and pressure conditions have been reported in literature [22, 24, 25]. Chemical species characterization is done using gas chromatography, mass spectrometry or molecular-beam mass spectrometry (MBMS) [26]. These experimental insights along with extensive modeling and computational efforts have contributed significantly to the present understanding of soot formation mechanism. The exact mechanism of soot precursor formation leading to soot inception and growth is detailed in the next section.

Parallel to the chemical kinetic studies of soot formation, quantitative studies characterizing soot physical properties have also been reported. Quantitative measurements of soot like volume fraction, particle size and number densities are critical properties contributing to the carcinogenic nature of soot. Additionally, soot measurement data is imperative for development and validation of soot formation models. For instance, information about soot number density, surface area, and particle size are important for understanding soot nucleation, growth and coagulation processes. Optical diagnostic techniques comprise the principal tools utilized for measuring soot particle properties (size and volume fraction). Optical methods include the classical laser scattering/extinction techniques (LS/E) and more recently laser induced incandescence (LII). In laser scattering and extinction, soot properties are calculated based on the Rayleigh theory for isotropic spheres with diameters much smaller than the laser wavelength. The choice of detection wavelength is critical. Soot volume fraction $f_{v}$ can be deduced from extinction measurements if the soot refractive index is known. Additionally, soot volume diameter may be evaluated using scattering measurements. However, the assumptions of this theory are more valid in the early stages of soot inception than in later stages when the individual soot particles tend to form aggregates. Extinction is determined over a finite path length, which requires local spatial resolution or spatial uniformity, or a mathematical method for inversion of path-integrated extinction [14. These drawbacks severely limit the use of LS/E in varied experimental conditions to obtain all soot related information.

The more recently developed laser induced incandescence (LII) is the more preferable optical method for quantitative measurements of soot volume fraction because of its conceptual simplicity and ease of implementation to obtain spatially and temporally resolved measurements 27. LII technique involves the detection of thermal radiation from soot particles that have been heated to vaporization temperatures using high energy pulsed laser [28]. Several studies have demonstrated that the LII signal is approximately proportional to the soot volume fraction [29]. Moreover, the time-resolved LII signal has been shown to be a measure of the particle size [28. A large particle diameter corresponds to lower cooling rate and hence a slower decay of the LII signal. A comparison of experimental decay curves with theoretically calculated curves could be used for particle size evaluation 
30. However, this theory is limited by the uncertainties associated with the influence of inaccurate flame temperature on the evaluated particle size, since the cooling process is strongly dependent on the flame temperature.

In-situ optical diagnostic techniques are unsuitable for gaining reliable particle morphology and size information because of the inherent oversimplification in the optical theory, that loses applicability in case of soot aggregates. Spatially and temporally resolved data of particle size distribution (PSD) evolution, especially in the range of $1-10 \mathrm{~nm}$, is crucial to correctly predict and validate soot inception and growth mechanisms 31. Hence, in-situ optical techniques, that are mainly good for soot volume fraction measurements, are usually combined with thermophoretic sampling for size measurement using TEM [32. Thermophoretic sampling and subsequent morphology analysis using transmission electron microscopy imaging is fundamental to accurately model soot cooling for LII data analysis [33. By itself, TS/TEM, is insufficient because it cannot provide information about local particle concentration. Also, the ex-situ nature of this technique, and the time consuming sampling and analysis makes TS/TEM unattractive. Thermophoretic sampling and analysis by TEM imaging is primarily useful for studying soot morphology. Studies using TS/TEM have provided substantial understanding of soot aggregate morphology and its fractal properties, especially the degree of carbonization or crystallite growth of soot [34, 35. This experimental method involves rapid insertion of a small colder probe into a desired flame location to thermophoretically collect soot (soot depositin due to existence of temperature gradient) and subsequent analysis of particles deposited onto the grid under a transmission electron microscope (TEM) [36]. The advantage of this method is that no prior knowledge of particle bulk density and refractive index is required. Other similar studies employing thermophoretic sampling of soot and subsequent analysis using AFM (atomic force microscopy) have been reported as well.

Recently, Scanning Mobility Particle Sizer (SMPS) has received considerable attention as a potential ex-situ soot measurement tool [37, 38, 39, and has been used for soot measurement in this study. Studies employing SMPS to follow soot evolution have been conducted mostly in flame environments [37, 40, 41, 42, 43, although, a few studies using flow reactors have been reported as well [44, 45]. The primary advantage in using SMPS as a diagnostic tool is rooted in its ability to probe particles smaller than $10 \mathrm{~nm}$, which is not possible with optical diagnostic techniques, mainly due to lack of reliable optical properties of newly incepted soot. Besides the ambiguity in soot optical properties, light scattering/extinction techniques are also accompanied by loss of smaller particles with the formation of larger soot particles. Another limitation of LS/E and LII techniques is that these only provide reliable soot volume fraction information, which by itself is insufficient to understand soot growth and destruction processes [38. A growing interest in soot particle size measurement using SMPS has resulted in the development and optimization of probe sampling techniques. A detailed discussion of this is provided in subsequent sections.

Another powerful diagnostic tool that has found use in in-situ soot size distribution measurements is Small-angle Neutron/X-ray scattering [46, 47, 48]. In fact, a combined use of aerosol mass spectrometry techniques and Small Angle Neutron/X-Ray Scattering facilitates simultaneous investigation 
of soot particle size distribution evolution and its chemical composition [49]. These recent advancements in soot measurement techniques allow an in-depth investigation of soot inception and mass growth processes, thus providing detailed experimental data required for advanced numerical solutions of soot formation dynamics.

\subsubsection{Modeling Studies}

Detailed modeling of fuel pyrolysis and soot formation has been an area of active research. Formation of soot is a highly complex process. However, a substantial amount of experimental work in conjunction with computational studies has advanced the general understanding soot formation process. The most popular soot formation theory was proposed by Frenklach et al [50], and is summarized here. Soot formation process may be conceptually viewed as comprising of two major components- gas phase chemistry leading to soot inception, and soot particle dynamics. Gas phase chemistry provides the connection between fuel combustion and appearance of incipient soot, whereas soot particle dynamics involves the growth/consumption of soot particles via surface reaction, and particle coagulation as described by aerosol theory. Figure 1.1 gives a simplified overview of the main steps involved in soot formation. It is intuitive that an accurate prediction of soot evolu-

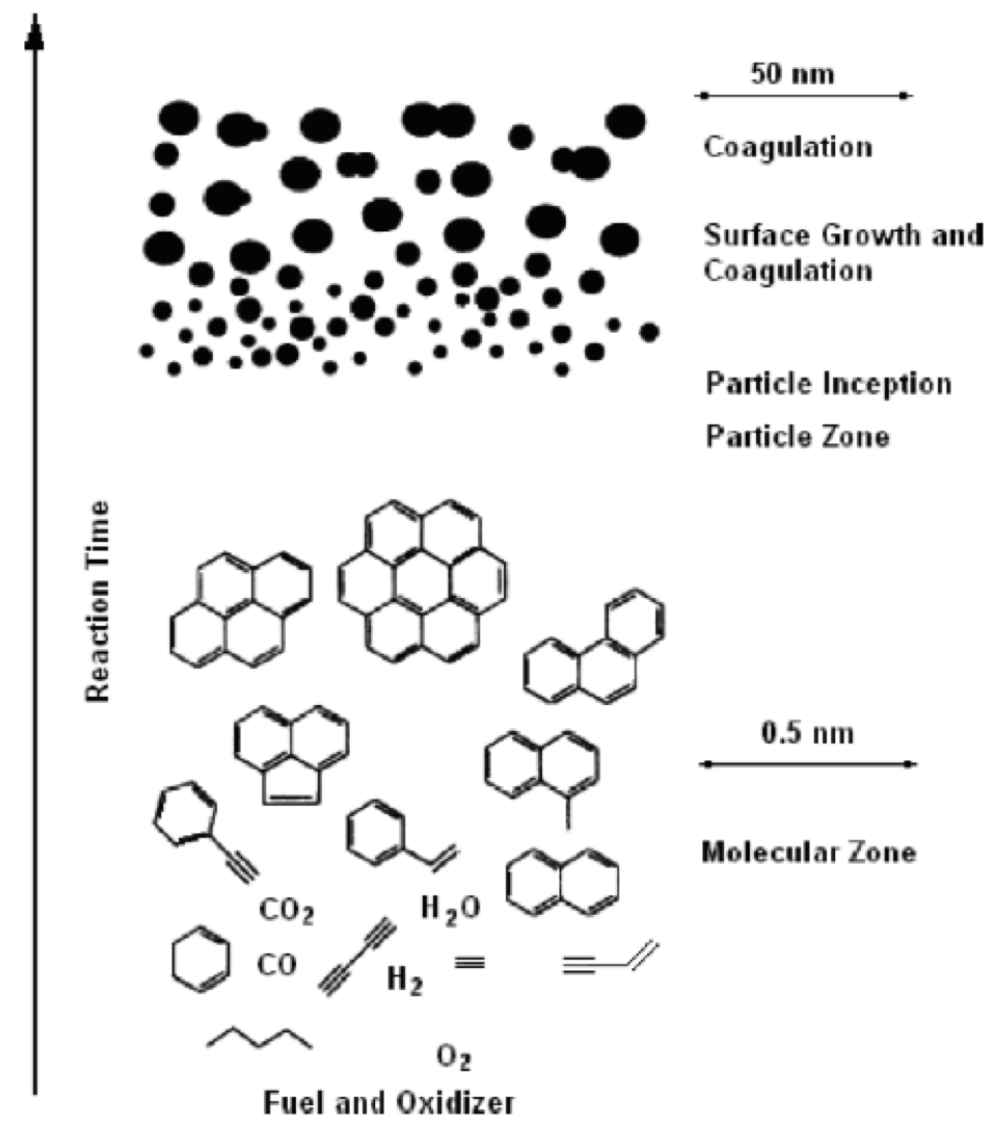

Figure 1.1: Steps involved in soot formation [1]

tion necessitates a detailed description of the fuel breakdown path (and hence gas phase chemistry) 
leading to gas-phase PAH formation [51]. Soot inception involves the formation of first aromatic ring, its subsequent growth via surface reactions to a prescribed size and finally the coagulation of PAH molecules leading to soot nucleation. Consequently, the formation of the first aromatic ring is often perceived as the rate-limiting step in soot nucleation [52]. Although, the kinetic pathway leading to the formation of first aromatic ring from smaller aliphatics varies depending on the parent fuel, yet experimental evidence show that some dominant steps are common to most fuel pyrolysis. Researchers concur that $\mathrm{C}_{2} \mathrm{H}_{2}$ is the principal component for reaction pathway of $\mathrm{PAH}$ formation from smaller aliphatics [53]. This idea was initially suggested by Berthelot [12] and has since then gained wide acceptance. Experimental characterizations of flames/shock tube pyrolysis products have shown that acetylene and diacetylene are the major species in sooting flames, that is, soot formation occurs in environments rich in acetylene. In fact, Frenklach showed that the following reaction,

$$
\mathrm{C}_{3} \mathrm{H}_{3}+\mathrm{C}_{2} \mathrm{H}_{2} \rightarrow c-\mathrm{C}_{3} \mathrm{H}_{5}
$$

[54] is a potential pathway for the initial ring formation. Thermodynamic equilibrium analysis shows that this reaction plays the dominant role in the formation of first aromatic ring for most fuels. Although acetylene is widely accepted as the key soot precursor, and is the premise of this study, polyenes have also received attention as possible gas soot precursor. Krestinin proposed that polyenes should be the dominant soot precursors by citing their fast growth through simple reactions, and the high reactivity of polyenes in polymerization reactions [55].

Once the first aromatic ring forms, planar growth of the aromatic ring to larger PAH progresses through the well-known Hydrogen Abstraction/Carbon Addition (HACA) mechanism, and PAH coalescence. In the presence of oxygen containing species, mainly $\mathrm{OH}$, depletion of aromatic species occurs, which in turn delays nucleation [56. However, Frenklach identified that relatively small quantities of molecular oxygen in high-temperature pyrolytic environments may, in fact, promote soot formation by creating radical pool (especially $\mathrm{H}$ atoms). Evidently, the chemistry involved in soot formation in premixed flame is fundamentally different from that in diffusion flames because, in the former scenario, soot precursor formation through fuel decomposition is in direct competition with oxidative attack on precursors. Soot formation rates in premixed flames are reduced with increasing flame temperature as a result of the dominant the oxidative attack on precursors. This is in contrast to diffusion flames where increasing flame temperatures promote soot formation rates through increased pyrolysis rates $[57$.

Nucleation, which is defined as the transition of gas-phase species to solid particles, occurs after the PAH molecules have grown to a prescribed size. The popular opinion is that soot nucleation is invoked by the irreversible dimerization of 4-membered PAH- pyrene [58, 59, 60]. Hence, pyrene is deemed as the soot precursor. Molecular dynamic simulations and experimental results have confirmed that the pyrene coalescence is an adequate explanation for the initial step for soot inception.

Akin to the growth of PAH, newly nucleated soot particles grow in size and accumulate mass by surface growth via Hydrogen Abstraction/Carbon Addition (HACA) mechanism [61, 62. This too 
has been proved through numerous experimental studies that show surface growth in environments of acetylene abundance [56, 63. Findings by several researchers using different flame conditions are consistent with HACA pathway for soot surface growth. Offsetting surface growth is oxidation of soot particles, which occurs predominantly by $\mathrm{O}_{2}$ molecules and $\mathrm{OH}$ radicals [64. It is worth pointing out that gas phase kinetics is pertinent to accurate soot nucleation and soot growth predictions, because it provides the species that define these processes.

Particle coagulation falls under the category of coalescent growth and hence, aerosol dynamics theory is used to analyze this phenomena. Coagulation dynamics is described by the Smoluchowski equations [65, wherein the ratio of the mean free path to the particle radius is the vital factor. Hence, coagulation is a function of pressure. Free molecular regime is used to describe coagulation at low pressure, while at high pressure, the continuum region is a more valid approximation. Unlike surface growth and oxidation, coagulation does not affect carbon mass accumulation [54, 66. Soot coagulation is characterized by a simultaneous increase in mean particle size, and a reduction in particle number density of soot. In terms of the observed soot particle size distributions (PSDs), the overall effect of different components of soot formation process may be summarized as followsgas phase kinetics control nucleation, and hence the number of incipient soot particles, coagulation affects the evolution of particle number density; the bulk mass accumulated in soot is determined primarily by surface reactions, growth and oxidation, and the ultimate soot size is affected by competing surface reactions and coagulation [50].

In this context, it is relevant to mention that the soot particle size distributions (PSD) obtained from burner stabilized flames and flow reactors are qualitatively different. PSD obtained from burner stabilized flames are consistently bimodal [41, 56, 67, whereas soot generated in laminar flow reactors are reported to be unimodal [6]. However, bimodality of soot obtained from flames were shown to be sensitive to temperature and height above the burner. In particular, higher temperatures favored unimodality. Additionally, at lower heights (from the burner) soot PSDF is unimodal as a result of particle nucleation. Bimodaliy has been explained to be a direct consequence of competing nucleation and soot surface growth mechanisms. It has also been argued that bimodality in heavier sooting flames arises from competition between surface mass growth and particle-particle coagulation 68. It is clear that soot particle size distribution is very sensitive to reaction conditions, and are capable of conveying critical information about the active soot formation processes. 


\section{Chapter 2}

\section{Motivation}

Recently, our group used a nano-SMPS to study evolution of soot particle size distribution (PSD) during ethylene pyrolysis and oxidation in a novel reactor under atmospheric pressure conditions, and temperatures ranging from $1100 \mathrm{~K}-1200 \mathrm{~K}[6]$. The present work aims to further the understanding of soot formation processes in flow reactors by investigating the influence of operating conditions like pressure and temperature; as well as identifying the role of principal soot precursors like acetylene. Primarily, the objectives of this study are two-fold -

1. The first part of this study focuses on exploring the influence of pressure on soot formation during ethylene pyrolysis

2. The second part of this study aims to characterize the effect of acetylene in soot formation mechanism. To this end, experiments involving ethylene doped with acetylene pyrolysis were conducted, and the resulting soot particle size distribution was studied.

\subsection{Effect of Pressure}

Soot formation in combustion systems is influenced by several parameters. While there is sufficient information available on the effect of parameters like temperature and fuel molecular structure, not much is known about the true effect of pressure on sooting behavior of fuels. Even though practical combustion devices like gas turbine combustors operate at elevated pressures, pressure related information is severely limited.

As has been the trend in other combustion studies, the available investigations of pressure effects on soot formation are conducted mostly in laminar flames and shock tubes [69, 70, 71, 72, 73]. This is mainly because of their ability to provide easily controllable experimental conditions, which allow the investigator to isolate the influential parameters. Experimental efforts using laminar flames to study the influence of pressure have been limited because of problems with flame stability, flame narrowing and high soot loading at higher pressures. Smith and coworkers were among the first investigators who studied soot formation in laminar counter-flow flames at elevated pressure [74. They 
found that sooting tendency of a particular flame (that is a particular fuel) depends on pressure, and suggested the existence of a critical pressure above which non-sooting flames become sooting. Studies since then, mainly involving co-flow flames, have consistently found comparable results for flames of different fuels. Most of these studies use soot volume fraction and carbon conversion as the measure of sooting tendencies [75, 76]. Additionally, these studies conclude that pressure has a significant effect on the characteristics of co-flow diffusion flames, particularly on flame structure and soot concentrations. An increase in pressure causes flames to become narrower and curved inwards. Flame narrowing itself enhances soot formation. Due to the combined effect of flame narrowing and reaction kinetics, non-sooting flames at atmospheric pressure can transform into sooting flames at higher pressures 21 .

Problems with high-pressure combustion experiments are not restricted to experimental design, conventional diagnostic techniques like LII are rendered inaccurate under these conditions due to the uncertainty of heat transfer model at higher pressure [77, 21, 78]. Combustion under elevated pressures often results in heavily sooting and smoking flames. Under such conditions, scattering and absorption by soot particles may affect LII signals [79]. In light of the aforementioned limitations surrounding experimental measurement of soot at elevated pressures, this study aims to develop a laminar flow reactor with varying orifice diameter for studying pressure effects on soot formation. Online sampling with SMPS is used to obtain soot particle size distributions. This experimental set up offers a promising technique for studying soot formation under elevated pressure and relatively low temperatures (around 1200K), which corresponds to supercritical endothermic fuel cracking.

\subsection{Effect of Acetylene on Soot formation during Ethylene Pyrolysis}

Several studies have examined the effect of aromatics and oxidants on soot formation processes by doping ethylene or acetylene flames with small amounts of benzene [80, methanol, toluene, etc [81, 23, 82. The idea behind such experimental investigations is to acquire consequential data that can be used to extract information about soot chemistry and the related species. These experiments have succeeded in providing valuable information about the relevant soot oxidation pathways, role of aromatic rings in $\mathrm{PAH}$ formation, and in determining the relative importance of proposed soot formation mechanisms involving these species. The second part of this study was undertaken to investigate the role of acetylene in soot inception and growth through HACA mechanism [83. Besides validating soot formation models, use of acetylene as a dopant is also motivated by the fact that acetylene and ethylene have been found to be among the major intermediates formed from oxidation and pyrolysis of hydrocarbon fuels [84]. In order to identify the influence of acetylene, two phases of experiments were conducted. First study involved the pyrolysis cases of acetylene-doped ethylene (acetylene formed 14\% of total fuel mix), the second phase studied the soot formation from pyrolysis of pure ethylene. These studies are carried out in a micro-flow straight tube reactor at atmospheric pressure. A comparison of sooting tendencies of acetylene-doped ethylene pyrolysis cases with baseline ethylene pyrolysis cases will shed light on the importance of acetylene as the principal 
species for soot formation and growth. Such comparison will be useful in capturing the impact of acetylene on soot formation processes like nucleation and growth. By quantifying this difference, relative importance of acetylene can be established. 


\section{Chapter 3}

\section{Experimental Set-Up}

This study consists of two separate experimental setups, one for elevated pressure pyrolysis experiments, and the other for atmospheric pyrolysis of acetylene doped ethylene. A micro-flow straight tube reactor with a converging-diverging section was used for the elevated pressure investigations. The study involving atmospheric pyrolysis of ethylene and acetylene-doped ethylene involved a simpler micro-flow straight tube reactor. Online sampling of soot was accomplished using nano-Scanning Mobility Particle Sizer (n-SMPS). The SMPS consisted of a Classifier (model 3080), nano-Differential Mobility Analyzer (n-DMA model 3085) and a nano-Condensation Particle Counter (n-CPC model 3788). The SMPS was set to dual-blower mode, with the sheath flow rate of $6 S L P M$ and the inlet sample flow rate of $1.5 S L P M$ for best resolution. The probe sampling technique was the same for both studies. The general experimental setup maybe divided into three main systems the gas feeding system, quartz reactor, and finally the sampling probe and particle size distribution measurement device. Figure 3.1 depicts the general setup for both experiments. The elevated pressure MFTR has an additional orficie of size $231 \mu \mathrm{m}$ at the reactor exit for achieving choked flow conditions.

\subsection{Atmospheric Pressure Reactor}

The atmospheric pyrolysis reactions were conducted in a quartz tubular reactor of $4 \mathrm{~mm}$ inside diameter and $60.96 \mathrm{~cm}$ in length. It was placed in an electrically heated oven, consisting of 6 modular heaters, each of which was of 4 inches long. The reactor was maintained at the target temperature using six Omega PID controllers connected to K-type thermocouples placed adjacent to the outside wall of the tube. With this design, reaction residence times maybe varied by changing total feed gas flow rates, or by changing the length of reactor hot section. The pyrolysis experiments were performed for $4 \%$ (by volume) ethylene and acetylene fuel mix, diluted by $96 \%$ inert nitrogen gas. Ethylene and acetylene flow rates were in the ratio of $6: 1$, that is, acetylene formed $14 \%$ of the fuel mixture. This ratio was determined based on calculation of dodecane pyrolysis. Dodecane was chosen as a representative of large hydrocarbons that are present in jet fuels. The value of $4 \%$ fuel mix (by volume) was selected with the intention of producing a substantial amount of soot that allows appreciable detection by the SMPS. High dilution (96 volume $\%$ inert $N_{2}$ ) of feed gas is employed 


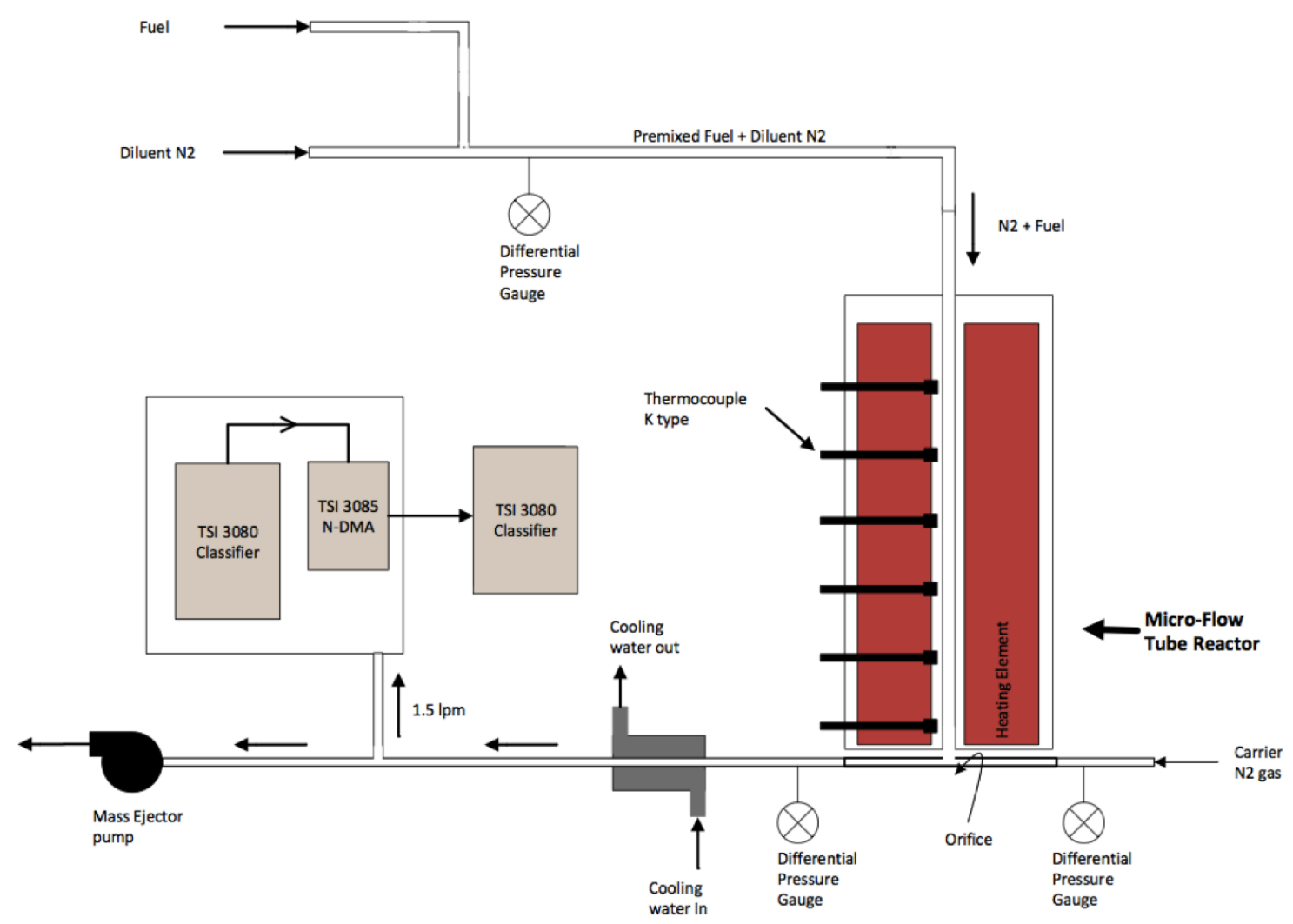

Figure 3.1: Schematic of experiment set-up for micro-flow atmospheric tube reactor (MFTR)

to suppress self-sustaining combustion. Residence time was changed by controlling the reactant flow rate.

The gas feeding system consists of three Sierra mass flow controllers for controlling the flow of acetylene, ethylene and diluent nitrogen. The reactant gases were mixed prior to being fed into the quartz reactor. A flame arrestor was connected upstream of the reactor feed for safety purposes. A pressure gauge was also connected upstream of the reactor entrance to monitor reaction pressure so as to avoid accidental pressure buildup. The flow conditions for the experiments correspond to low Reynolds number $(<<2000)$, hence the reactions occur in laminar flow regime. However, reaction process characteristics like residence times were estimated using plug flow assumption. A more detailed discussion about the plug flow assumption is done in section 3.6 .

The sampling probe was placed horizontally at the exit plane of the reactor, taking care to carefully align the orifice with the reactor outlet. The sampling probe and associated technique is described in detail section 3.3 . 


\subsection{Elevated Pressure Reactor}

The micro-flow tube reactor used for elevated pressure experiments is a straight quartz tube with a converging nozzle (231 $\mu \mathrm{m}$ orifice) at the tube exit. The inner diameter of the straight section of this tube is $4 \mathrm{~mm}$ and the total reactor length (heated section) is $18 \mathrm{in}$. The orifice allows choked flow operation, and in doing so the reactor can be back-pressured to any desired value. This simple design facilitates reactions conditions of constant high pressure at relatively lower temperatures. As long as the upstream pressure is above the critical pressure required for attaining choked conditions at the orifice, a set maximum mass flow through the reactor is achieved, which depends on the diameter of the converging section. Consequently, the residence time for a particular reactor arrangement is fixed for a given operating temperature. Either changing the nozzle diameter can vary the reaction residence time, or the reactor length may vary the residence times. Upstream pressure can be adjusted by varying the feed gas cold velocity. All cases involving elevated pressure were run for $2 \%$ ethylene (fuel) pyrolysis in $98 \%$ inert carrier nitrogen bath.

The reactor was electrically heated using 5 modular heaters, and Omega PID controllers connected to K-type thermometers were used to maintain the reactor at the target temperature. The gas feeding system set up was similar to the atmospheric reactor. A pressure gauge connected upstream of the reactor entrance was used to monitor the process pressure. The flow conditions for the high pressure experiments lie in the laminar flow regime, however, for simplicity, plug flow assumption is used to model reaction parameters like residence times. The sampling system arrangement was the same as for the atmospheric experimental conditions.

\subsection{Sampling Probe Design and Dilution}

The sampling probe used in all the current experiments was developed and validated in a previous study by our group [6]. This sampling probe and the associated sampling technique was based on the design developed by Zhao and coworkers [38. They used a cylindrical stainless steel tube (similar to the original design of Kasper et al [85]) horizontally placed in the flame for online sampling of flame gases through a micrometer-sized orifice. The flame gas enters the probe due to negative pressure across the orifice, and is diluted by cold nitrogen flow immediately on entering. Subsequent studies have validated and improved the accuracy of this sampling procedure.

The probe used in our study was a stainless steel cylindrical tube with OD $3 / 8 \mathrm{in}, 0.65 \mathrm{~mm}$ thickness and a length of $30 \mathrm{~cm}$. It was installed horizontally at the exit plane of the tube reactor. In order to facilitate drilling of orifice, a small rectangular groove was milled in the center of the tube of depth $0.5 \mathrm{~mm}$. The diameter of the orifice was $0.25 \mathrm{~mm}$ and the thickness of the wall surrounding it was $0.15 \mathrm{~mm}$.

The dilution system comprised of diluent $N_{2}$ supply, a mass ejector system and 2 differential pressure gauges $(0-250 \mathrm{~Pa})$, placed upstream and downstream of the orifice, for maintaining precise control over suction pressure across the orifice. The small suction pressure across the orifice drove the flow 
of soot laden product gas into the probe. On entering the probe, the gases were rapidly diluted and cooled down by the carrier nitrogen gas. Rapid dilution of soot sample is crucial to reduce soot particle losses by diffusion and coagulation. Additionally, rapid cooling down of the hot gas quenches chemical reaction, and hence prevents further growth/consumption of soot particles. The flow rates of the nitrogen gas (10SLPM to $30 S L P M$ ), along with the negative differential pressure (25 to $200 \mathrm{~Pa}$ ) across the orifice were varied to obtain a range of dilutions. A copper cooling block was inserted downstream of the orifice to further cool the soot sample. Downstream of cooling block, the incoming sample flow was split into two parts with a small portion of $1.5 S L P M$ being fed to the SMPS using silicone conductive tubes, while the remaining bulk flow was exhausted through a pump connected downstream of the SMPS. The temperature of the sample gases at SMPS inlet was always measured to be in the range of $303 K-306 K$.

The probe placement and proper orifice alignment is crucial for successful soot sampling. Due to the small size of the orifice, exact orifice alignment with the reactor exit becomes difficult. In order to verify the proper positioning of the orifice before starting any experiment, nitrogen in passed through the reactor and sampled through the orifice. If the orifice is not aligned correctly, ambient air enters the probe (through the orifice) instead of nitrogen that is flowing through the reactor. Figure 3.2 shows the particle size distributions of air and nitrogen.

The horizontal placement of the sampling probe causes the flow ahead of it to become a stagnation

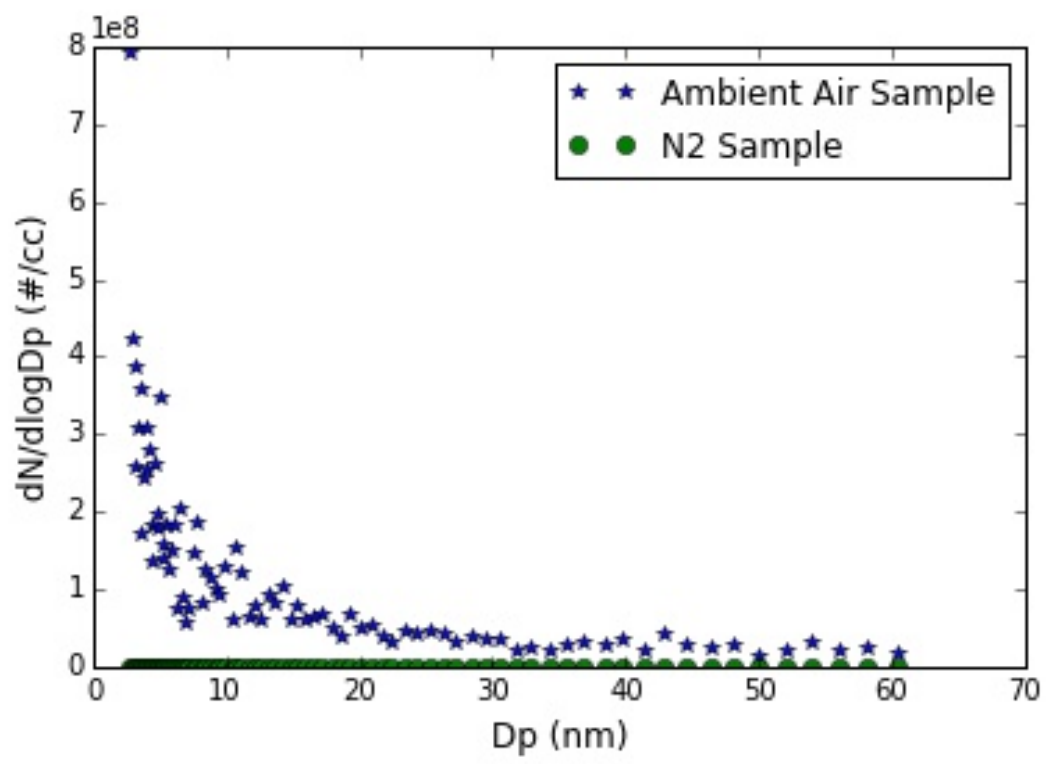

Figure 3.2: Comparison of Particle Size Distribution of Ambient Air and Pure Nitrogen

flow. A direct advantage of this stagnation flow is the additional drop in temperature, which minimizes thermophoretic wall losses of the soot particles in the orifice 37. Furthermore, a fundamental difference in our probe design compared to the design of Zhao et al is the thickness of the wall 
surrounding the orifice. The aspect ratio for our probe orifice was $0.6(<1)$, while the aspect ratio reported by Zhao et al was 4.768 . The lower aspect ratio in our study is desirable to minimize the time for soot particles to traverse the orifice thus causing negligible diffusive losses in the orifice wall.

\subsection{Scanning Mobility Particle Sizer}

Scanning Mobility Particle Sizer is a high resolution sizing device. This study uses the nano-SMPS for online sampling of soot particles obtained from varied experimental conditions. The current SMPS consists of TSI 3080 Electrostatic Classifier and nano-Differential Mobility Analyzer, and a TSI 3080 nano-Water based Condensation Particle Counter. The soot aerosol particles first pass through an inertial impactor into the electrostatic classifier and finally to the nano-WCPC. The SMPS was set to allow an inlet sample flow rate of $1.5 L P M$ and sheath flow rate of $6 L P M$ in a dual blower mode to reduce diffusive particle losses by reducing transport time. Under these settings, the $\mathrm{n}$-WCPC had lower size limit of $3 \mathrm{~nm}$. A typical particle size spectrum was obtained over a $120 \mathrm{sec}$ up-scan and a $15 \mathrm{~s}$ down-scan.

$$
D_{50}=\sqrt{\frac{9 \pi S t \mu}{4 \rho_{s} C Q}}
$$

\subsubsection{Impactor}

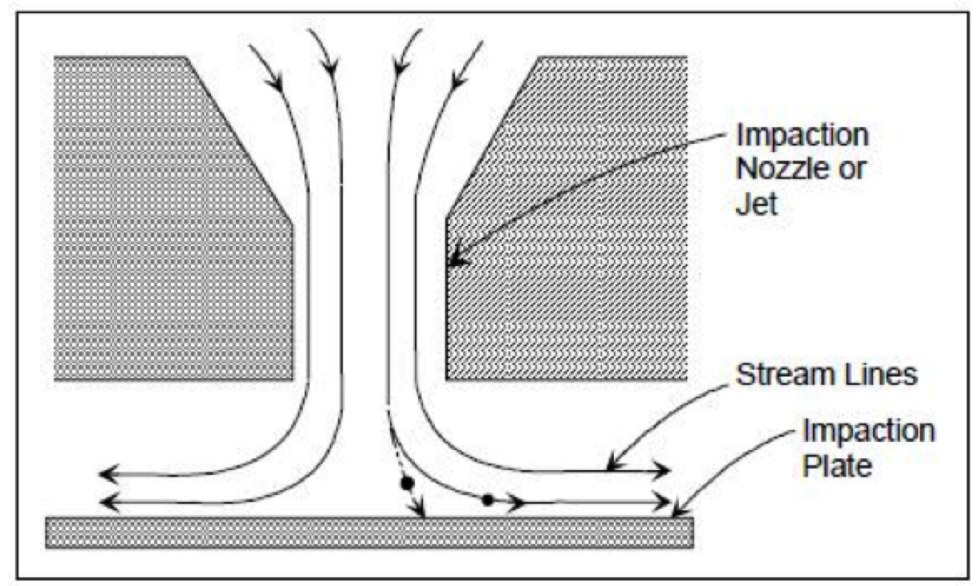

Figure 3.3: Cross-Sectional view of Inertial Impactor [2]

$$
C=1+K n[\alpha+\beta \exp (-\gamma / K n)]
$$

The aerosol sample is fed to the nano-SMPS through an inertial impactor. As the sample enters the impactor, it is accelerated through a nozzle towards a flat impaction plate. At the impaction plate, the incoming flow is deflected that forms 90 degree bend in the flow streamlines. Larger particles 
(with more inertia) fail to follow the new streamlines, and deposit on the impactor. The aerodynamic particle size at which such impaction occurs is termed as the cut-point diameter [86], and is given by equation 3.1. In the equation $D_{50}$ is the cut-point diameter ( $50 \%$ efficiency considered), $S t$ is the Stokes number $(0.23), \rho_{s}$ is the particle density $\left(\mathrm{g} / \mathrm{cm}^{3}\right), Q\left(\mathrm{~cm}^{3} / \mathrm{s}\right)$ is the volumetric flow rate, $D_{p}$ is the particle diameter $(\mathrm{cm}), \mu$ is the gas viscosity $\left(\right.$ dynes $\left./ \mathrm{cm}^{3}\right), W$ is the nozzle diameter $(\mathrm{cm})$ and $C$ is the Cunningham Slip Correction factor [87, as given in equation 3.2 . Here, $\alpha=1.142, \beta$ $=0.558, \gamma=0.999, K n$ is the Knudsen number: $K n=2 \lambda / D_{p}$. Figure 3.3 shows a cross-sectional view of Inertial Impactor [2. Clearly, the cut-point diameter is a function of nozzle diameter and impactor flow. Hence the impactor serves as a separator to remove larger particles from the sample flow entering the classifier.

\subsubsection{Electrostatic classifier}

$$
Z=\frac{n e C}{3 \pi \mu D_{p}^{\text {mobility }}}
$$

After passing through the impactor, the polydisperse soot aerosol enters the classifier. The first part

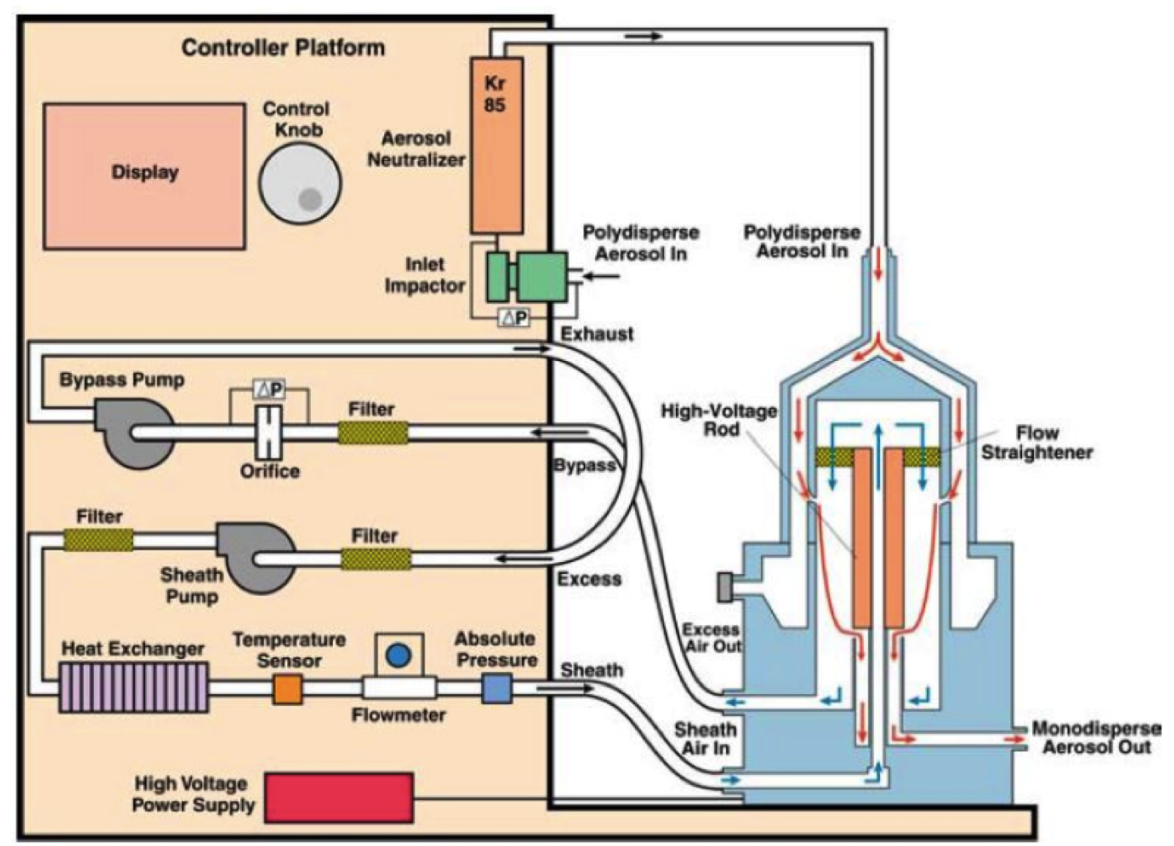

Figure 3.4: Flow schematic for the TSI 3080 Electrostatic Classifier with nano-DMA in dual- blower mode 3 ]

of the electrostatic classifier is a $K r 85$ Bipolar Charger (neutralizer). Here, the sample is subjected to a high concentration of bipolar ions generated by the radioactive bipolar charger. The aerosol particles frequently collide with these ions due to their random thermal motion. Consequently, the particles reach an equilibrium charged state with a known bipolar charge distribution. Next, the charged aerosol passes into the differential mobility analyzer. The nano DMA consists of two concentric metal cylinders, with the inner cylinder maintained at a controlled negative voltage, and 
the outer cylinder is grounded. This establishes an electric field between the two cylinders. The charged polydisperse sample along with sheath air enters at the top, and flows down the annular space between the cylinders in a way such that the laminar aerosol flow surrounds the inner core of sheath air without any mixing. Positively charged particles in the sample aerosol are attracted through the sheath air to the negatively charged inner cylinder. The extent of acceleration of these charged particles depends on the amount of charge (which governs the amount of electric force), and the particle size (which controls the viscous forces). The particles precipitate at distinct axial positions along the length of the inner cylinder depending on the electrical mobility $\left(Z_{p}\right)$, classifier geometry and classifier flow rate. The exact relationship is given in equation 3.3 . where $n$ is the number of elementary charges on the particle, $e$ is the elementary charge $\left(1.6 \times 10^{-19}\right.$ Coulomb $)$ and $D_{p}^{\text {mobility }}$ is the diameter $(\mathrm{cm})$ of the particle measured by the SMPS [88. Particles with high electrical mobility precipitate out near the top portion of the inner cylinder, whereas those with lower mobility diameter collect at the bottom. Only particles within a narrow range of mobility diameter exit with the sheath flow at the bottom of the annular region through a small slit. Due to the narrow size range of the particles allowed to pass the DMA, the exiting sample is often referred to as monodisperse [89]. These particles (within a certain range of mobility diameter) are then transferred to the condensation particle counter, while the remaining particles are removed with excess air flow.

\subsubsection{Nano-Water Bases Condensation Particle Counter}

$$
\frac{P}{P_{s}}=\exp \left(\frac{4 \gamma M}{\rho_{c} R T d_{\text {Kelvin }}}\right)
$$

The aerosol exiting the DMA enters a nano-water based condensation particle counter that measures particle concentration. The working principle of CPC is motivated by the idea that growth of particles through heterogeneous condensation can be utilized for convenient detection of very small that are otherwise undetectable by conventional optical techniques. In the CPC, the aerosol particles are first saturated with water vapor, then the mixture is cooled causing the vapor to become supersaturated and condense onto particles, that leads to their ultimate growth. These larger particles are now capable of scattering sufficient light, and hence, can be detected by laser diode optical sensor. The smallest size detected by the CPC is controlled by the saturation ratio of the condensing vapor. This parameter is defined as the ratio of the actual partial pressure $P_{s}$ and the saturation pressure $P_{s}$ at a given temperature. In equation 3.4, $\gamma$ is the surface tension, $M$ is the molecular weight, $\rho$ is the density of the liquid, and $d_{\text {Kelvin }}$ is the Kelvin diameter 90. Kelvin diameter is the diameter of a droplet that neither grows nor evaporates at the saturation ratio. The nano-WCPC consists of a conditioner, a growth tube, and an optical detector (Figure 3.5. The conditioner is a cool region saturated with water vapor. Here, the aerosol sample is cooled with a thermo-electric device. The cooled sample then reaches the growth tube, which is a heated section with wetted walls. In this section, the small cool particles serve as nuclei for condensation and subsequent growth. After growing to an optically detectable size, these particles pass through a laser light beam, and scatter light onto a photo detector, that allows their subsequent counting. The n-WCPC counts single particles with continuous, live-time coincidence correction up to 400,000 particles $/ \mathrm{cm}^{3}$. 


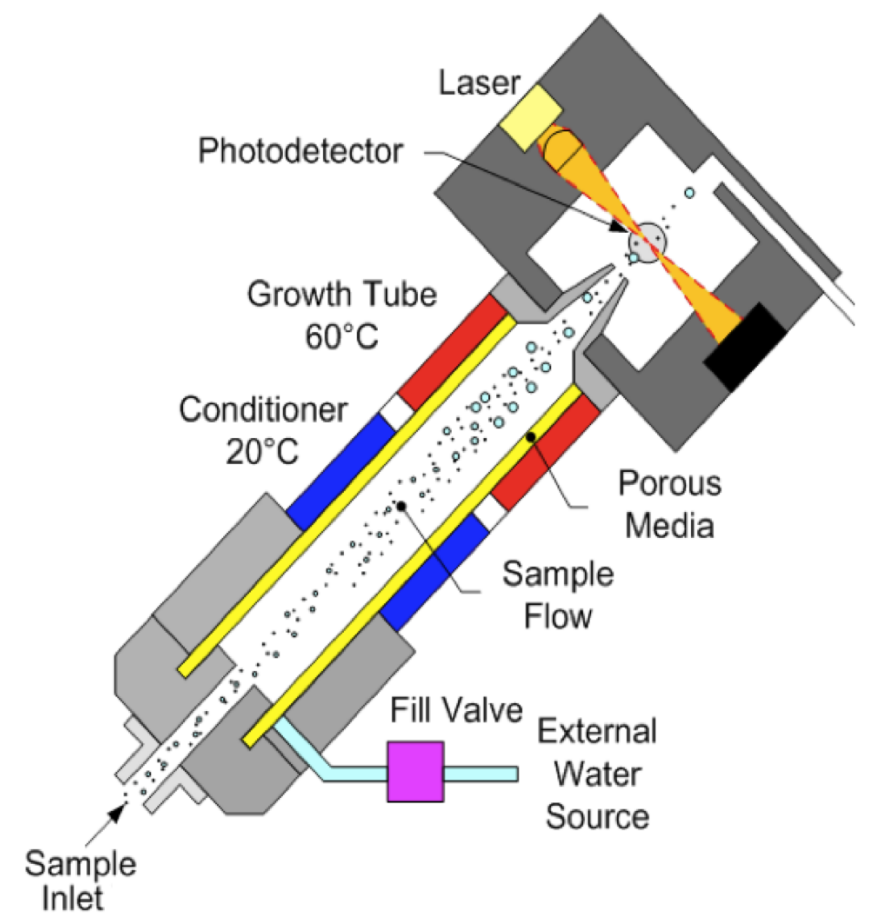

Figure 3.5: Flow schematic for the nano-CPC [4]

\subsubsection{Mobility Diameter}

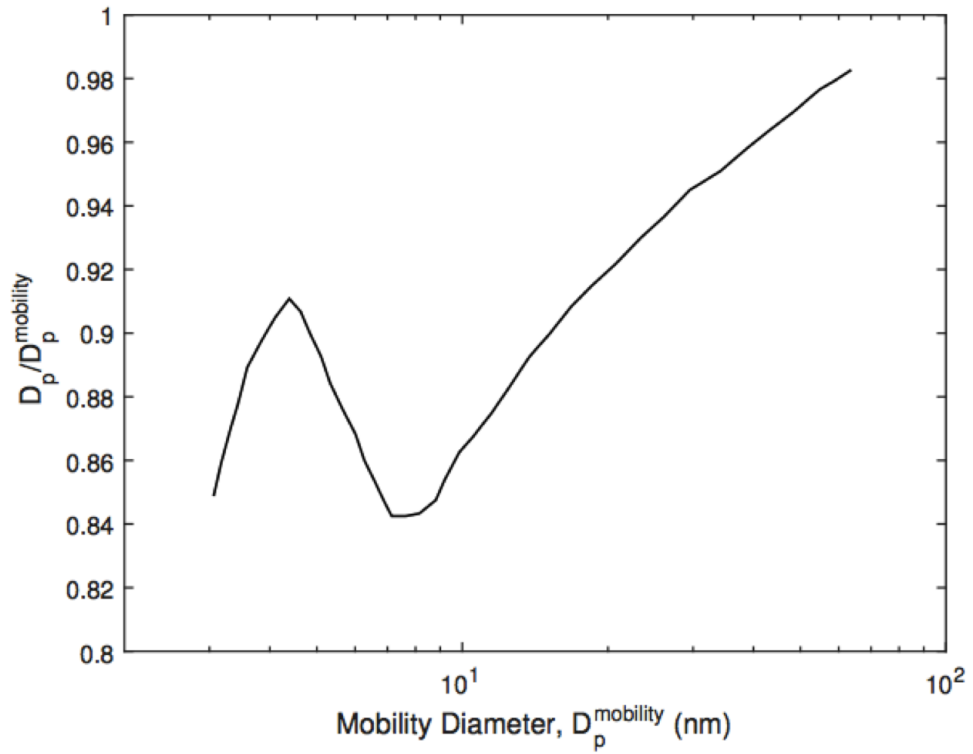

Figure 3.6: Relationship between Mobility Diameter and True Particle Diameter [5] 


$$
Z=\frac{3}{2} \sqrt{\frac{k T}{2 \pi m_{r}}} \frac{p n e}{D_{p}^{2} \omega_{a v g}^{(1,1)}}
$$

Mobility diameter as measured by the SMPS is based on the electrical mobility of the particles. When a charged particle moving through a fluid is subjected to an electric field, it quickly reaches a terminal velocity to counterbalancing of viscous forces by the electric forces [91. Electrical mobility diameter can be obtained by equating drag force to electrical force. Li et al [92, 5] showed that for nano-sized particles, mobility diameter differs from true particle diameter. Using Knudsen number for an ideal gas, equation 3.5 92 was derived to model particle mobility as a function of its diameter. Here, $k$ is the Boltzmann constant, $T$ is the temperature, $m_{r}$ is the reduced mass, $D_{p}$ is the proposed true diameter, $p$ is the pressure, and $\omega_{a v g}^{(1,1)}$ is the average reduced collision integral. Using these two equations, true diameter can be obtained from the mobility diameter information. Figure 3.6 shows the relationship between both these diameters. All mobility diameters obtained from the SMPS were corrected using this fit.

\subsection{Calibration of Orifice Flow Rate}

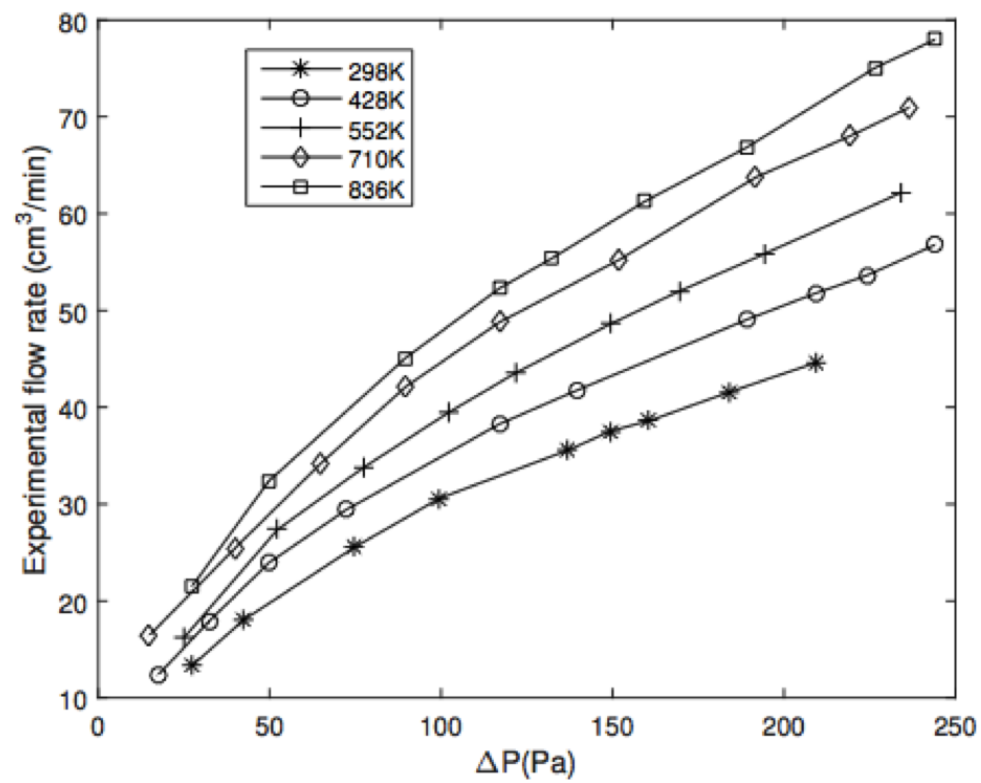

Figure 3.7: Experimental Flow rate through orifice versus differential pressure across orifice for 250 $\mu \mathrm{m}$ orifice 6 ]

$$
Q_{0}=A\left(c_{1} \frac{\Delta P}{T^{0.8}}+c_{2} T^{0.5} \Delta P^{0.5}\right)
$$

On entering the sampling probe under the effect of suction pressure, the hot soot laden gases are 


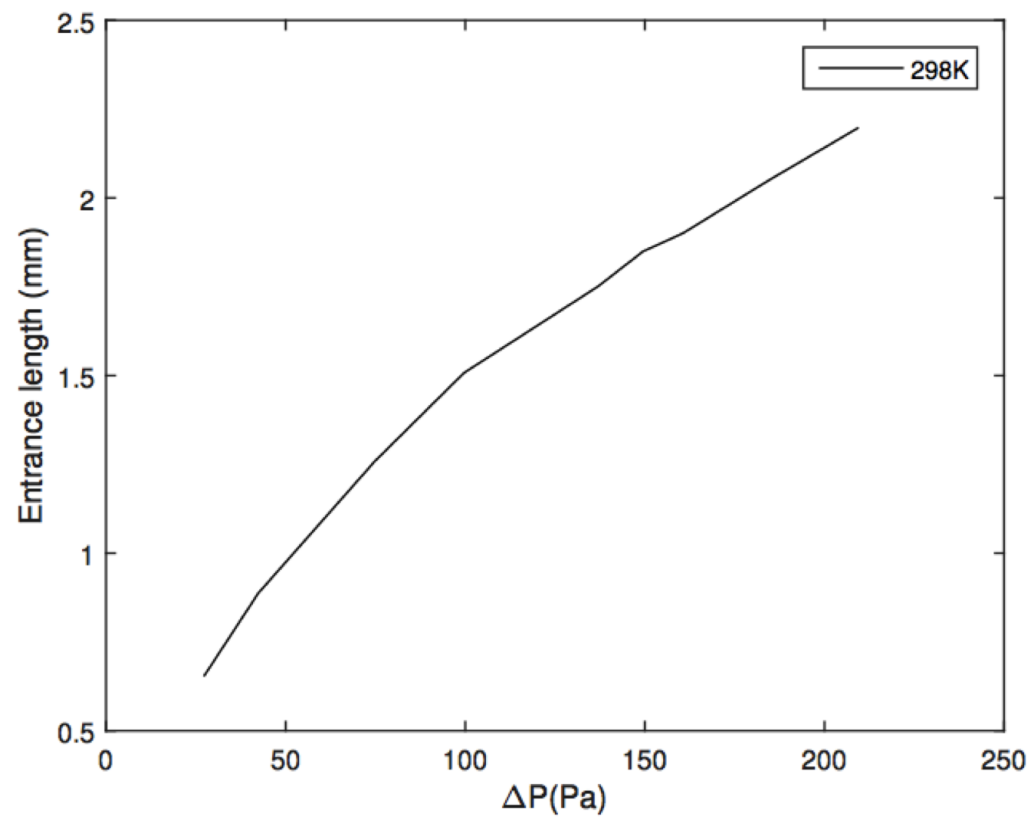

Figure 3.8: Variation of entrance length of flow through orifice as a function of pressure across orifice 6

immediately diluted by cold carrier nitrogen gas flow. The nitrogen gas flow ranges from $10-30$ $S L P M$. As mentioned before, dilution is crucial for mitigating particle losses due to coagulation and diffusion. Hence an estimation of dilution ratio is necessary to obtain the final absolute soot number densities. Dilution ratio is defined as the ratio of volumetric flow rates of main nitrogen flow through the probe and the hot gas coming in through the orifice. The procedure for calibrating flow rate through the orifice involved plugging one end of the probe and connecting its other end to a pump through a flow meter in purge mode. Initially, two identical pressure transducers were connected upstream and downstream of the orifice (equidistant from the orifice) to measure the flow rates of atmospheric air as a function of pressure across the orifice. However, it was noted that both pressure gauges gave similar suction pressure (within experimental error range), hence subsequent calibrations (at different temperatures) were conducted using only one pressure transducer connected upstream of the orifice. The observed flow rates were reported in a previous study [6], and are presented here. It was shown in the same study that the flow through the orifice is still developing. Figure 3.7 shows the calculated variation of entrance length of incoming flow as a function of suction pressure at 298 $\mathrm{K}$ This is due to the small aspect ratio of the orifice (250 micron diameter and 150 micron orifice length), resulting in entrance length greater than the orifice thickness. The flow rate was found to be a function of only temperature and differential pressure across orifice, as given by equation 3.6 [6. Here, $c_{1}$ and $c_{2}$ are the calibration constants found to be 0.8 and 0.054 for the orifice diameter of $250 \mu \mathrm{m}$ and $\mathrm{A}$ is the cross sectional area of orifice [6]. 


\subsection{Plug Flow Assumption}

The flow rates for both sets of studies are very small, hence laminar flow exists under these conditions. Laminar flow is associated with Poiseuille velocity distribution, which may result in residence time distributions as a result of the parabolic velocity profile [93. However, for simplified reaction kinetic analysis, a plug flow approximation is used. Under plug flow assumption, the mean flow velocity (of the parabolic velocity profile) allows the inter-conversion of axial coordinate to residence times. Plug flow assumption may be verified by an analysis of axial and radial diffusive tendencies (at target reaction temperatures) [94, 22. The reactor design assures minimal axial dispersion in the fully developed laminar flow regime. In the present design, convective species transport is much greater than diffusive species transport along the reactor axis. Axial dispersion number is defined as the ratio of diffusive transport rate and convective transport rate (inverse of Peclet Number) 95. The axial dispersion number for all our experimental cases ranged from $10^{-3}$ to $10^{-4}(<<1)$. Radial homogeneity requires diffusive time scales to be shorter than chemical reaction time scales 96. Diffusive time scale was estimated to be around $80 \mathrm{~ms}$, whereas the reaction times range from $215-315 \mathrm{~ms}$. The above analysis shows that plug flow assumption is fairly valid for atmospheric cases. However, it is important to point out that under high-pressure conditions, radial diffusive time scales become comparable to the reaction time scales, which may cause radial inhomogeneity. Under this condition, plug flow assumption may be an oversimplification.

\subsection{Heat Transfer and Temperature Ramp-Up Section}

The reactors for both set of studies had identical straight tube section, except for the converging nozzle at the end of high-pressure reactor. On entering the reactor, premixed carrier gas/fuel is heated in a temperature ramp up section. It was shown in earlier studies (both high pressure and atmospheric MFTR) that temperature measurements outside and inside the tube under flowing conditions differed by less than $5 \mathrm{~K}$ (in the constant temperature region), with endothermic pyrolysis cases showing a slight drop in temperature while exothermic oxidation cases showing slight increase [6. 97. Information of the temperature ramp up section is crucial for an accurate estimation of the reaction residence times.

To this end, a numerical 1-D heat transfer analysis was performed to estimate the temperature ramp up section length. The one dimensional heat transfer code was based on Newtons law of cooling for convective heat transfer from the reactor wall to the reactant gas. The flow is assumed to be developed in both the fluid dynamic sense and thermal sense. The thermally developed assumption was verified by calculating thermal length for both high pressure and atmospheric pressure cases. The entrance length was found to be at most $0.5 \mathrm{~cm}$ for all cases, whereas the ramp up section is 10

$\mathrm{cm}$ for atmospheric pressure experiments and $15 \mathrm{~cm}$ for high-pressure experiments. The entrance length is insignificant compared to the relevant flow domain length, which validates the thermally developed argument. The overall heat transfer coefficient was calculated based on fluid thermal properties and Nusselt number. Due to the thermally developed assumption, Nusselt number value of 3.66 was used for flow with uniform wall temperature [98. 


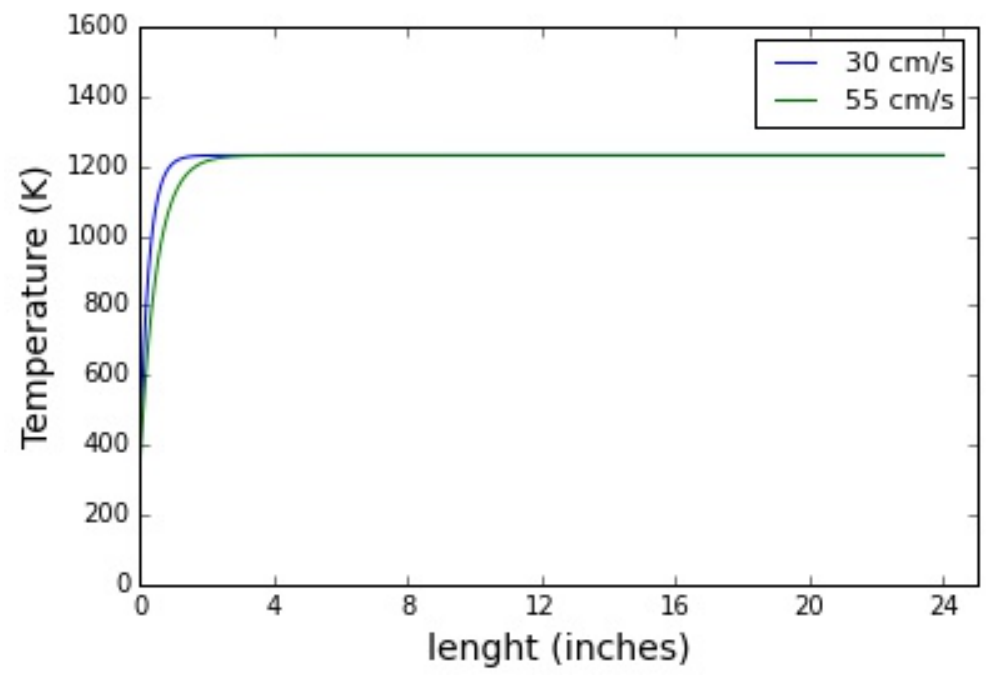

(a) Calculated Temperature Profile under Nitrogen Flow for Atmospheric Pressure Experiments at $1230 K$

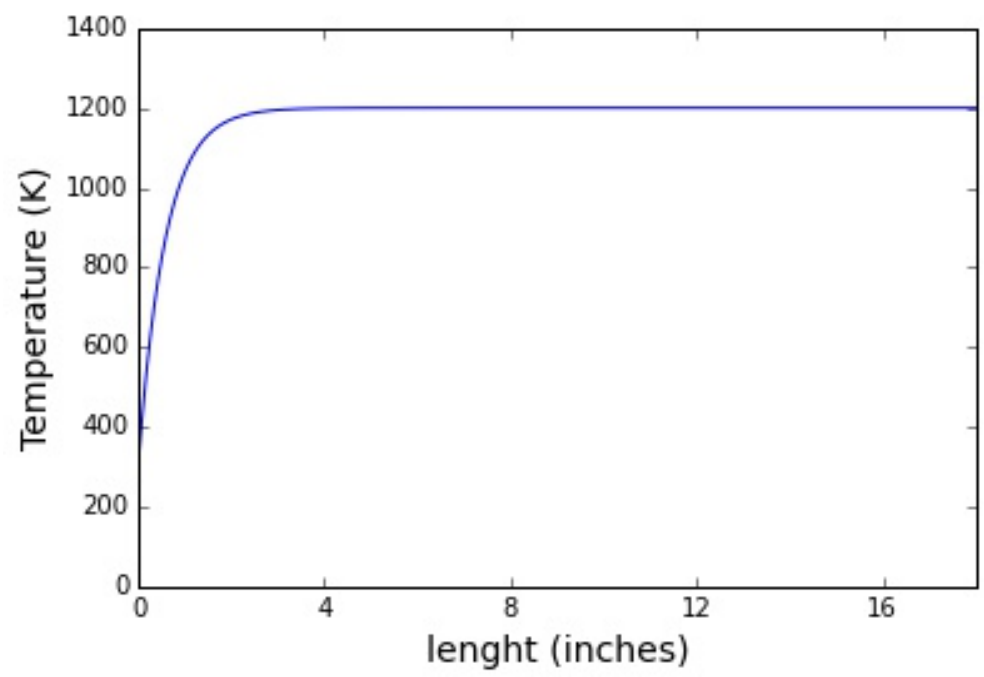

(b) Calculated Temperature Profile under Nitrogen Flow for High Pressure Experiments at $2 \mathrm{~atm}$ and $1200 K$

Figure 3.9: Numerical Solution of Temperature Profile under Nitrogen Flow

Figure 3.9 shows the numerically solved temperature profiles for both experimental conditions. The first figure shows the temperature profiles for nitrogen flow at $1230 \mathrm{~K}$ with feed velocity of $30 \mathrm{~cm} / \mathrm{s}$ and $55 \mathrm{~cm} / \mathrm{s}$, which corresponds to the range of feed gas velocities in this study. It can be seen from both the temperature profiles that the ramp up section is around $10 \mathrm{~cm}$ (approximately $4 \mathrm{in}$ ) for all the cases. The second figure shows the calculated temperature profile for nitrogen flow at $1200 \mathrm{~K}$ and $2 \mathrm{~atm}$ pressure. The temperature ramp up section in this case is around $15 \mathrm{~cm}$ (approximately 
$6 \mathrm{in}$ ). Reaction is assumed to begin at $1000 \mathrm{~K}$ because several studies have shown the formation of hydrogen and other soot precursors from ethylene pyrolysis for temperatures around $1000 K$ [99, 100]. The calculated residence time accounts for the time spent by reactants in the portion of temperature ramp-up section corresponding to $1000 K-1200 K$. 


\section{Chapter 4}

\section{Results}

\subsection{Dilution Effects}

Dilution ratio is defined as the ratio of flow rates of main nitrogen flow through the probe and the sample flow through the orifice. The orifice flow rates were determined in a previous study, which were used to calculate the exact dilution ratios $\left(f_{D}\right)$ as in equation 4.1 [6]. Here, $\operatorname{Tr}$ is the ratio of

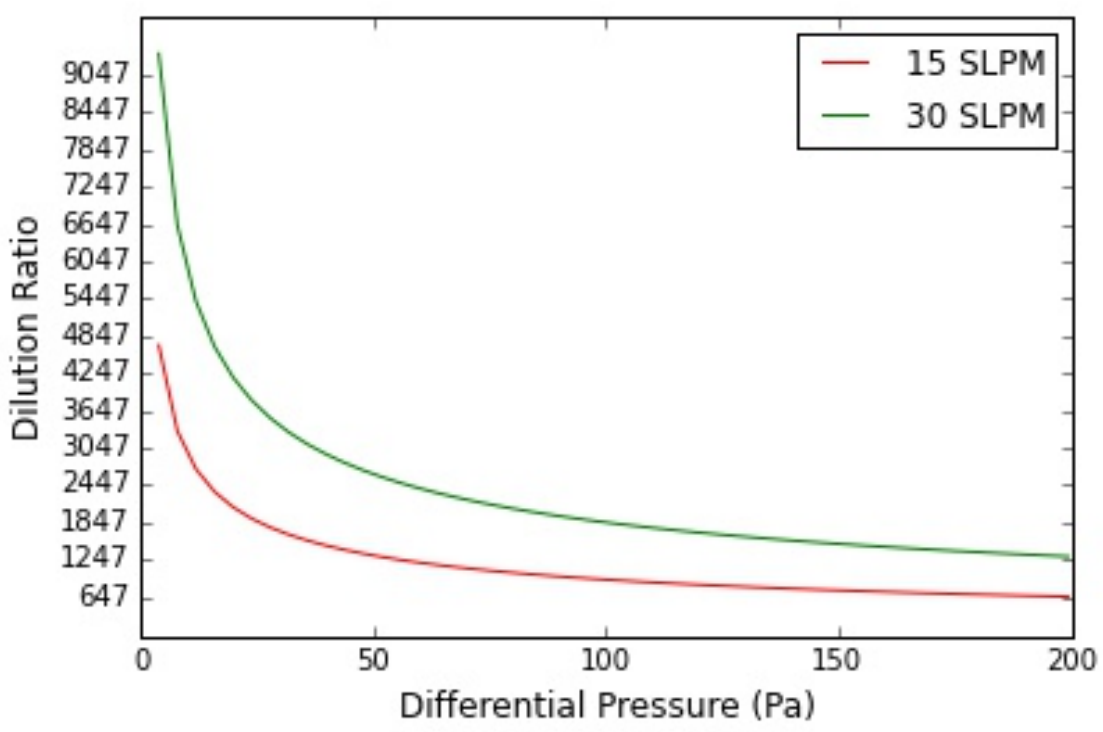

Figure 4.1: Range of Dilution-Ratios for Diluent $N_{2}$ flow rates

inlet gas temperature and the carrier gas $\left(N_{2}\right)$ temperature $(298 K)$. The inlet gas temperature was measured for different operating reaction temperature cases. For an isothermal reaction temperature of $1200 \mathrm{~K}$, the temperature of the sample soot laden gases entering the probe was measured to be approximately $886 K$. For $1210 K, 1220 K$ and $1230 K$, the sample soot laden gas temperatures were measured to be approximately $894 K, 901 K$ and $907 K$ respectively. $Q_{c}$ is the flow rate of cold 
nitrogen at STP and $Q_{0}$ is the flow rate of flame gases calculated at the inlet temperature 80. Absolute number density of the soot is related to the number density reported by SMPS as in equation 4.2 [6]. where $N_{a}$ is the absolute number density of soot in the hot gas, and $N$ is the number density as reported by SMPS. $f_{w}$ is the multiplicative factor to account for diffusive losses, and is taken to be $1[6]$ in this study.

$$
\begin{aligned}
& f_{D}=\frac{Q_{c}}{Q_{0}} T_{r} \\
& N_{a}=\frac{f_{D}}{f_{w}} N
\end{aligned}
$$

As discussed previously, online sampling by SMPS is not trivial. Sampling issues like particle coagulation and diffusive losses are undesirable as these may change the particle morphology and size. Immediate dilution of the hot soot laden gas by a cold inert gas flow in the sampling probe is a widely used and validated technique to minimize particle losses by coagulation and diffusion [68, 101, 39. Cold $N_{2}$ gas at high flow rate enables instantaneous quenching of particle growth kinetics, while also minimizing the thermophoretic deposition of soot in the sampling line. Furthermore, it curbs diffusive losses by ensuring that convective time scales are much smaller than diffusive time scales (due to high flow rate of $N_{2}$ ). It was pointed out in section 3.3 that diffusional losses in the sampling orifice is minimal due to its small aspect ratio, and the fact that sample transverse time through the orifice is much smaller than the diffusive times in the orifice wall. The standard technique for obtaining an adequate dilution for each experimental case involves systematic increase in dilution ratio to a critical value after which there is no observable dependence of particles size distribution function on dilution. This method was followed for all sets of experiments. The critical dilution ratio was found to be in the range of $1.2 \times 10^{3}$ to $2.2 \times 10^{3}$ for soot studies involving elevated pressure, corresponding to nitrogen flow rates of $15 S L P M$ to $30 S L P M$. The critical dilution ratio for atmospheric reactions involving fuel mix varied from $0.85 \times 10^{3}$ to $1.9 \times 10^{3}$ (varies depending on the residence times and reaction temperatures), corresponding to nitrogen flow rates in the range of $10 S L P M$ to $22 S L P M$. Figure 4.1 shows the $N_{2}$ flow rates used in this study, and the corresponding dilution range. Although, these dilution ratios are smaller compared to those reported in flame studies, other studies have shown that this value can range from $10^{3}$ to $10^{4}$ depending on the combustion system 68. The smaller dilution ratios used in our study may be attributed to relatively smaller amount of soot generated in the MFTR as a result of short residence times (215 - $315 \mathrm{~ms}$ ).

Figure $4.2 \mathrm{a}$ presents the variation of absolute soot particle size distributions as a function of dilution ratios for $2 \%$ ethylene pyrolysis at $1200 \mathrm{~K}, 2.7 \mathrm{~atm}$ pressure. Figure $4.2 \mathrm{~b}$ shows the effect of dilution ratio on soot particle size distribution for reaction condition corresponding to acetylene - doped ethylene pyrolysis (total fuel mix forms $4 \%$ of reactant mixture) at $1220 \mathrm{~K}, 1 \mathrm{~atm}$ pressure. In Figure 4.2a, for the smallest dilution ratio (DR), the particle size distribution clearly corresponds to coagulation mode, as is evident from its shift towards larger diameters, and a much smaller number density relative to the PSDs corresponding to higher DR. As the dilution ratio is increased from 1075 to 2067, the size distribution for the same reaction condition shows an increase in the small diameter particles. Further increasing the DR beyond a critical point does not modify the PSDs. 


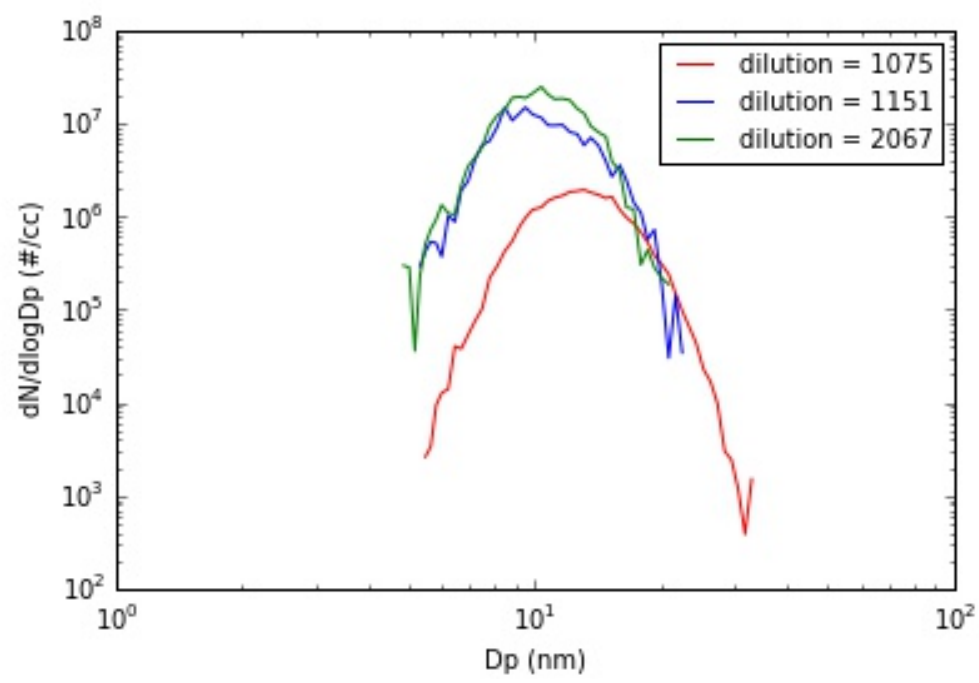

(a) Dilution Effect for elevated pressure experiments

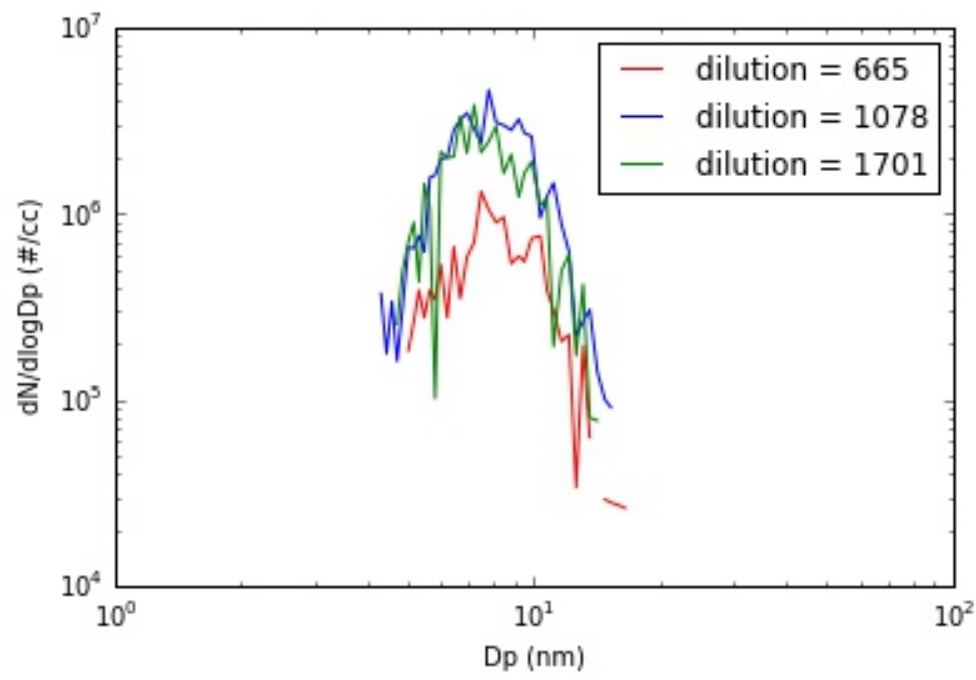

(b) Dilution Effect for atmospheric experiments.

Figure 4.2: Effect of Dilution

In fact, it can be seen that the PSDs corresponding to DR of 1151 and 2067 nearly superimpose. The mean diameter is $13.11 \mathrm{~nm}$ for the lowest dilution ratio, while for the higher dilution ratio, the mean particle diameter reduces to $10.5 \mathrm{~nm}$. Clearly, increasing the dilution ratio any further does not improve the quality of PSD. A similar trend is observed in Figure 4.2b. The PSD for the lowest dilution ( $\mathrm{DR}=665)$ is shifted towards the right and has a much smaller number density as compared to the other two PSDs, suggesting particle coagulation. In this case, the lowest dilution ratio of 665 corresponds to a mean particle diameter of $8.30 \mathrm{~nm}$. Further increasing the dilution ratio from 1078 to 1701 shows an increase in smaller particles, as well as a drop in the mean diameter, from 8.09 $\mathrm{nm}$ to $7.85 \mathrm{~nm}$ 


\subsection{Elevaed Pressure Experiments}

Table 4.1: Elevated Pressure Experimental Conditions

\begin{tabular}{|l|l|}
\hline Isothermal Temperature & $1200 \mathrm{~K}$ \\
\hline Reactant Composition & $2 \%$ Ethylene, 98\% Nitrogen \\
\hline Residence Time & $240 \mathrm{~ms}$ \\
\hline Reaction Pressure & Varied \\
\hline
\end{tabular}

The conditions for elevated pressure experiments are given in Table 4.1. As mentioned before, the upstream pressure was varied by varying the cold gas velocity. The pressure conditions tested in this study range from $2.5 \mathrm{~atm}$ to $2.8 \mathrm{~atm}$. Figure 4.3 compares the absolute soot particle size distribution and soot volume fractions at different pressure conditions. The soot particle size distributions are unimodal for these experimental conditions, as compared to the bimodal PSDs obtained from burner stabilized flames. This is in agreement with other soot studies using laminar flow reactors 6 . The figure (Figure 4.3 illustrates that as the operating pressure increases, both soot number densities and volume fractions progressively increase. The mean particle diameter $\left(D_{p}\right)$ increases from 8.47 $\mathrm{nm}$ to $11.7 \mathrm{~nm}$ as the reaction pressure is increased from $2.5 \mathrm{~atm}$ to $2.8 \mathrm{~atm}$. Hence, the mean particle diameter of soot scales with pressure by a power law relationship, $p^{n}$, where $n$ was calculated to be 2.79 by a log-log fit. The variation in soot properties with pressure is summarized in Table 4.2 .

Table 4.2: Soot Properties

\begin{tabular}{|c|c|c|c|}
\hline $\begin{array}{c}\text { Pressure } \\
(\mathrm{atm})\end{array}$ & $\begin{array}{c}\text { Mean Particle } \\
\text { Diameter }(\mathrm{nm})\end{array}$ & $\begin{array}{c}\text { Total Number } \\
\text { Density }(\# / \mathrm{cc})\end{array}$ & $\begin{array}{c}\text { Total Volume } \\
\text { Fraction }\end{array}$ \\
\hline 2.5 & 8.47 & $8.77 \mathrm{E}+06$ & $5.22 \mathrm{E}-06$ \\
\hline 2.6 & 9.65 & $9.27 \mathrm{E}+07$ & $7.28 \mathrm{E}-05$ \\
\hline 2.7 & 10.53 & $2.82 \mathrm{E}+08$ & $2.61 \mathrm{E}-04$ \\
\hline 2.8 & 11.7 & $8.69 \mathrm{E}+08$ & $9.03 \mathrm{E}-04$ \\
\hline
\end{tabular}

The increase in soot number density with operating pressure is indicative of the fact that increased reaction pressure (in this pressure range) accelerates soot nucleation rates leading to the formation of more soot precursors. A similar trend is observed in the soot volume fractions. However, total soot volume fractions appear to increase by the same order of magnitude as soot number densities. This suggests that the observed increase in soot volume fraction is a consequence of the increased soot number density. Moreover, the soot particle size increases, as is evident from the mean particle diameter. This phenomena is intuitive as an increase in the number of newly nucleated soot particles directly affects soot growth processes, and hence the particle size. A closer look at Figure 4.3 reveals that the particle size distribution corresponding to pressure $2.8 \mathrm{~atm}$ has a characteristic tail towards larger particle diameter. The sudden drop in number density towards larger particles clearly demonstrates that coagulation becomes prominent as pressure increases. The observed increase in soot number density is a direct indication of the formation of more soot nuclei as a result of the increase in apparent density of soot precursors due to elevated pressures. 


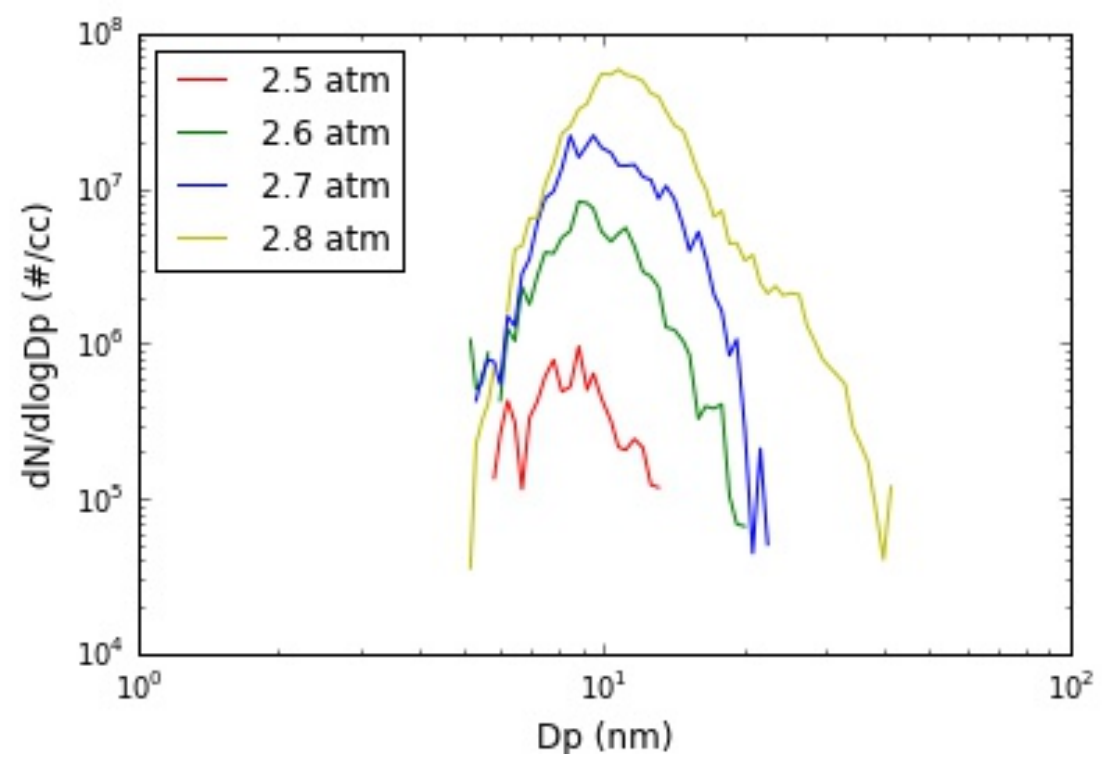

(a) Absolute Number Density.

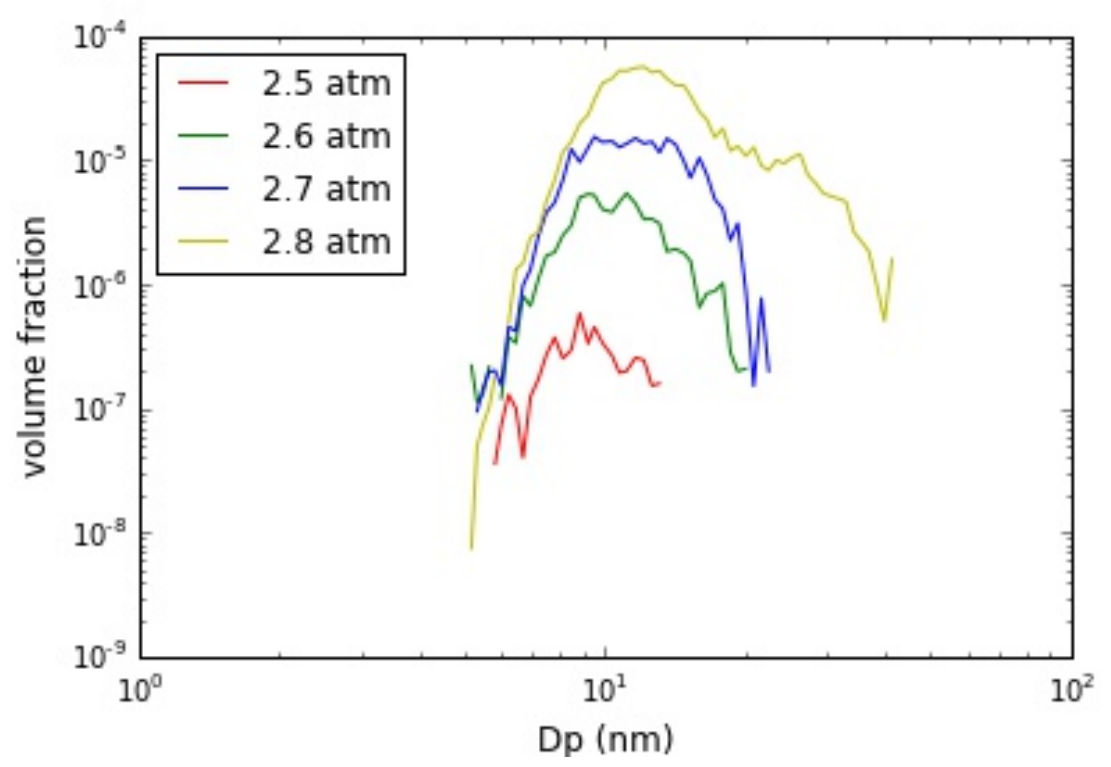

(b) Absolute Volume Fraction.

Figure 4.3: Comparison of Absolute Soot Particle Size Distribution and Soot Volume Fraction Distribution at Different Pressures 
The unimodality of the soot PSDs may be attributed to the laminar flow condition (poiseuille flow) and the resulting parabolic velocity distribution [102] inside the reactor. However, it is important to remember that bimodality arises due to the competition between soot inception and soot growth processes [38. Hence, the observed unimodality suggests that particle inception has completely ceased, and the observed mode corresponds to soot growth processes.

\subsection{Atmospheric Pressure Experiments}

The experiments involving atmospheric reactor are conducted in two parts, the first part involves pyrolysis experiments under different temperatures and residence times using acetylene-doped ethylene (4\% fuel mix) in $96 \%$ diluent Nitrogen. The ratio of ethylene to acetylene volume flow rates (mole fractions) was kept constant at 6 . The second part involves pyrolysis experiments of $4 \%$ pure ethylene (baseline case) under experimental conditions similar to those of acetylene-doped ethylene pyrolysis case. The soot particle size distributions obtained from both these sets of experiments are then compared in order to identify the qualitative differences brought about by acetylene doping. Such comparison will potentially help us in gaining an understanding of the manner in which acetylene affects soot formation process.

\subsubsection{Pyrolysis of Fuel-Mix}

Table 4.3: Experimental Cases \& Properties of Soot obtained from $\mathrm{C}_{2} \mathrm{H}_{2}$-doped $\mathrm{C}_{2} \mathrm{H}_{4}$ Pyrolysis

\begin{tabular}{|c|c|c|}
\hline Temperature (K) & Residence Times $(\mathrm{ms})$ & Mean Diameter $(\mathrm{nm})$ \\
\hline \multirow{3}{*}{1210} & 240 & 5.89 \\
& 280 & 6.41 \\
& 315 & 7.08 \\
\hline \multirow{5}{*}{1220} & 215 & 5.92 \\
& 240 & 6.56 \\
& 280 & 7.4 \\
& 315 & 7.85 \\
\hline \multirow{3}{*}{1230} & 215 & 6.15 \\
& 240 & 6.94 \\
& 280 & 7.95 \\
\hline
\end{tabular}

Table 4.3 summarizes the experimental cases tried in this study. As mentioned before, all experiments were conducted at atmospheric pressure using small amount of acetylene-doped ethylene ( $4 \%$ fuel mix; flow rate ratio of ethylene/acetylene is fixed at 6 ). As a side note, it can be seen from Table 4.3 that the lowest residence time for $1210 \mathrm{~K}$ is higher than the ones tried for $1220 \mathrm{~K}$ and $1230 \mathrm{~K}$, owing to the fact that any residence time lower than $240 \mathrm{~ms}$ does not produce detectable amount of soot. Similarly, any residence time higher than the ones listed below for each temperature case produces too much soot and smoking conditions. Hence, for safety considerations, experiments at higher residence times were not attempted. 
The effect of residence times on soot particle size distribution for each temperature is shown in

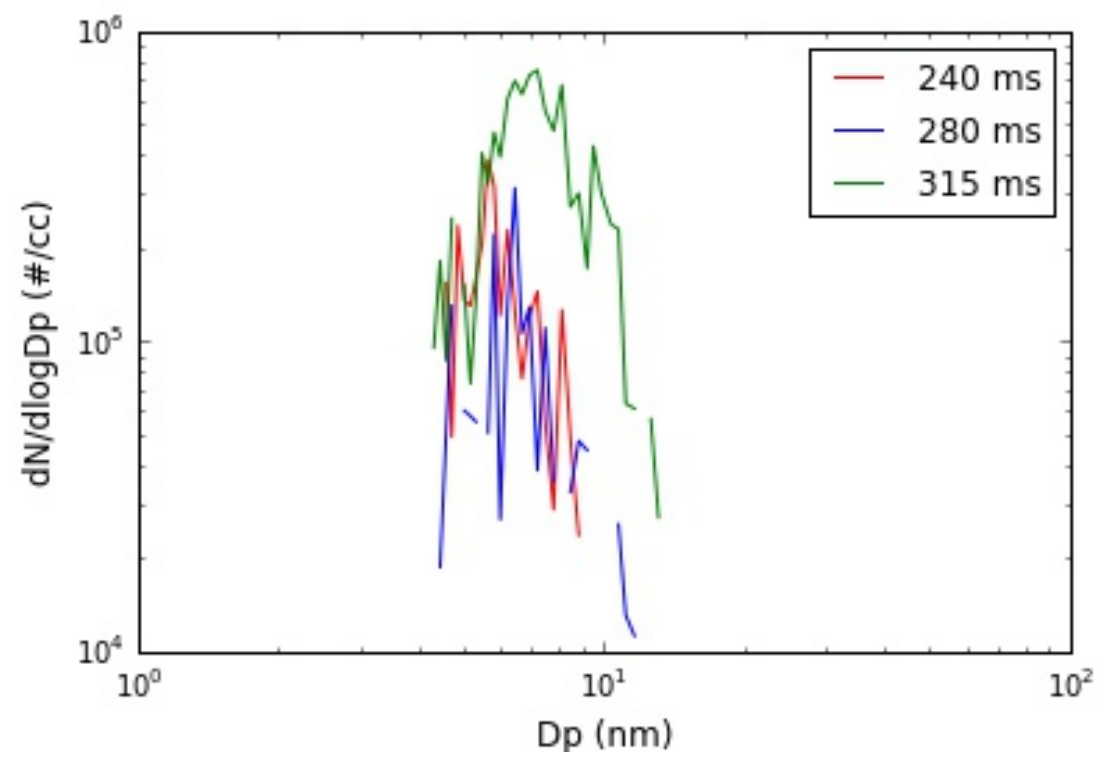

Figure 4.4: Absolute Soot PSDs as a Function of Residence Times for $\mathrm{C}_{2} \mathrm{H}_{2}$ - doped $\mathrm{C}_{2} \mathrm{H}_{4}$ pyrolysis at $\mathrm{T}=1210 \mathrm{~K}$

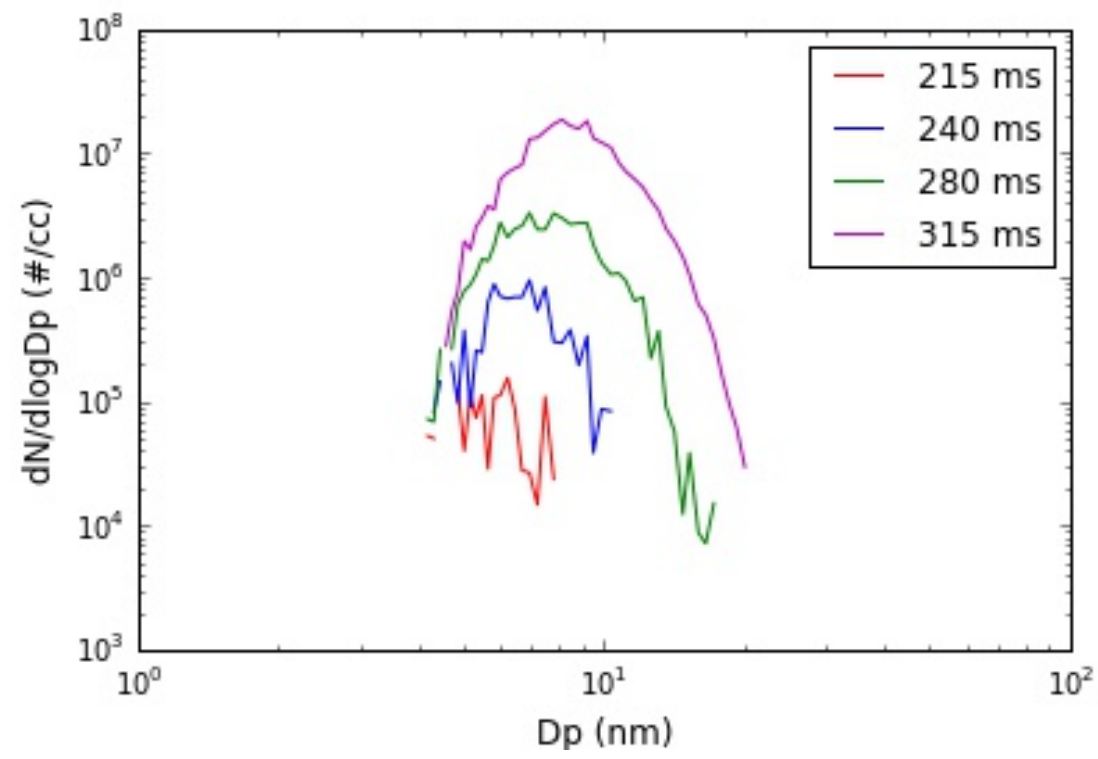

Figure 4.5: Absolute Soot PSDs as a Function of Residence Times for $\mathrm{C}_{2} \mathrm{H}_{2}$ - doped $\mathrm{C}_{2} \mathrm{H}_{4}$ pyrolysis at $\mathrm{T}=1220 \mathrm{~K}$

Figure 4.4. Figure 4.5 and Figure 4.6 corresponding to $1210 \mathrm{~K}, 1220 \mathrm{~K}$ and $1230 \mathrm{~K}$ respectively. Evidently, for all three temperatures, longer residence times result in enhanced soot number densities and mean particle diameters. It is readily observed that for temperatures $1220 \mathrm{~K}$ and $1230 \mathrm{~K}$, the 


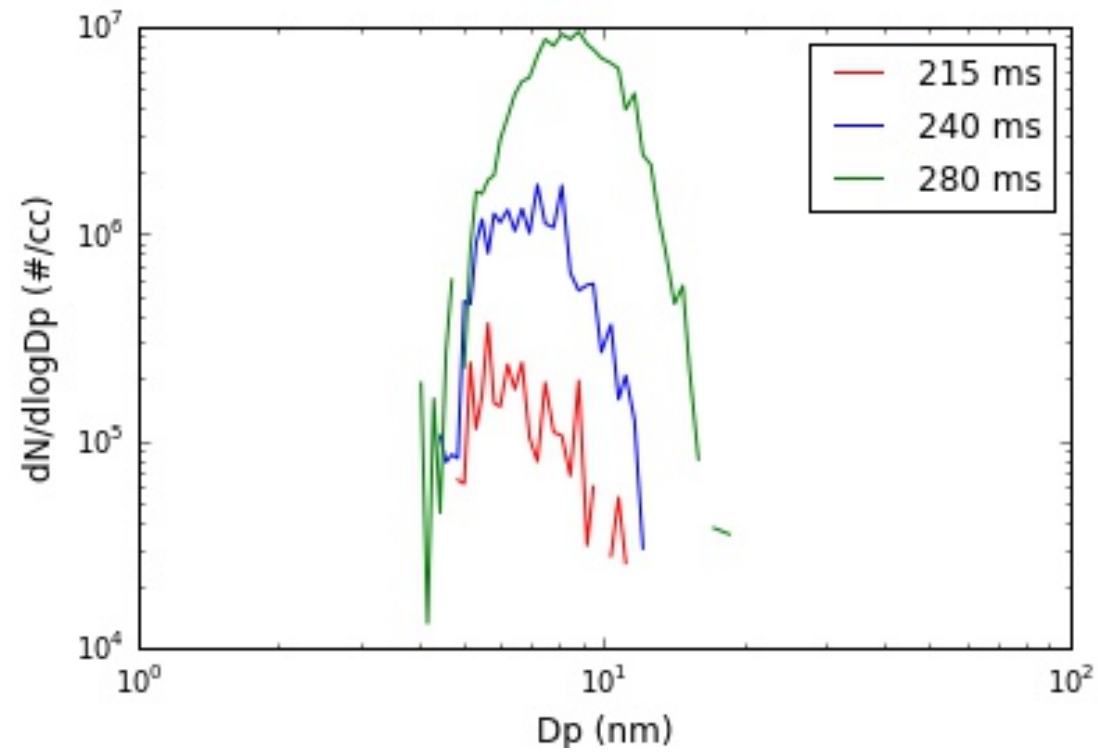

Figure 4.6: Absolute Soot PSDs as a Function of Residence Times for $\mathrm{C}_{2} \mathrm{H}_{2}$ - doped $\mathrm{C}_{2} \mathrm{H}_{4}$ pyrolysis at $\mathrm{T}=1230 \mathrm{~K}$

number densities increase by two orders of magnitude (from $10^{5}$ to $10^{7}$ ) over the entire range of residence times tested. Although there is an increase in the overall soot number density at $1210 \mathrm{~K}$, the change is not as pronounced. Additionally, all residence times at $1210 K$ have characteristic narrow particle size distributions. In contrast to this, particle size distributions at $1220 \mathrm{~K}$ and $1230 \mathrm{~K}$ become progressively wider (indicating larger soot particles) and steeper (indicating higher number densities) with increasing residence times. The observed trend is in agreement with the expectation that longer residence times allow nucleation of more soot particles. The residence time dependency of nucleation strength is amplified at higher temperatures. This phenomenon is expected due to the Arrhenius rate dependence of reaction pathways leading to the formation of soot precursors, and inception of soot.

Besides soot number densities, mean particle diameter also undergoes a noticeable increase due to variation in residence times. Mean diameters as a function of residence time at each temperature is reported in Table 4.3 . The observed increase in particle size could be a consequence of more incipient soot. In order to clarify the importance of soot growth on the increase in soot size, ultimate soot volume fraction was calculated for each case by integrating the differential volumes in each size bin (as generated by the SMPS). The total soot volume fraction increased as a function of residence time. Moreover, the variation in total soot volume fraction exceeded the variation in number densities. This point becomes apparent by comparing the soot volume fractions and number densities at residence times of $240 \mathrm{~ms}$ and $280 \mathrm{~ms}$ for each temperature case. At $1220 \mathrm{~K}$, soot number density increases from $9.8 \times 10^{6}$ to $7.2 \times 10^{7}$, while total volume fraction increases from $3.5 \times 10^{-} 6$ to $3.8 \times$ $10^{-5}$. Similarly at $1230 \mathrm{~K}$, number density changes from $2.07 \times 10^{7}$ to $1.38 \times 10^{8}$, whereas the volume fraction increases from $8.8 \times 10^{-6}$ to $7.9 \times 10^{-5}$. Hence, the amount of increase in soot volume 
fraction is 1.5 times greater than the amount of increase in soot number density. This suggests that the larger size of soot particles at longer residence times is a result of the combined intensification in soot nucleation and growth kinetics. However, this trend is not observed at $1210 \mathrm{~K}$. At this temperature, for the same residence time change, total volume fraction increases from $4.99 \times 10^{-7}$ to $7.1 \times 10^{-7}$, whereas the number density increases from $1.78 \times 10^{6}$ to $2.39 \times 10^{6}$. Hence, there was nearly equivalent increase in total volume fraction and number density. This implies that soot growth rates remain muted at this temperature.

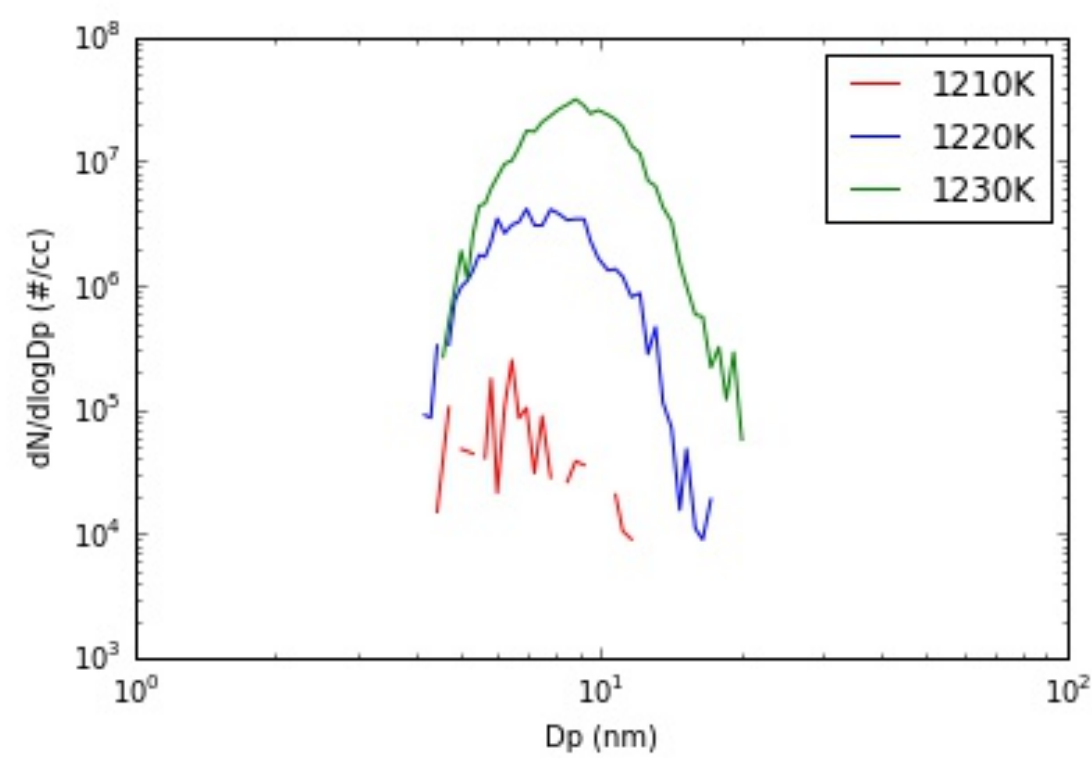

Figure 4.7: Effect of Temperature on Soot PSD for $\mathrm{C}_{2} \mathrm{H}_{2}$ - doped $\mathrm{C}_{2} \mathrm{H}_{4}$ pyrolysis at $280 \mathrm{~ms}$ Residence Time

The above discussion indicates that temperature is a critical parameter in determining the qualitative behavior of soot PSD. Figure 4.7 delineates the effect of temperature on soot particle size distribution at a residence time of $280 \mathrm{~ms}$. The figure reveals that a temperature rise from $1210 \mathrm{~K}$ to $1220 K$ induces a substantial enhancement in the particle size distribution properties. The soot PSD for $1220 K$ has a significantly higher peak than the PSD at $1210 K$ (number density increases by 5.5 times). Additionally, the particle size distribution becomes wider, due to the appearance of larger soot particles. This is further confirmed by an increase of almost $15 \%$ in the mean diameter (in going from $1210 K$ to $1220 K$ ). However, this effect weakens as temperature increases from $1220 \mathrm{~K}-1230 \mathrm{~K}$. In fact, the mean diameter changes by only $7.4 \%$, and the number densities are comparable. This suggests that at $1210 K$, nucleation and surface growth rates remain small. This in turn explains the reduced sensitivity of soot properties to residence time variation (in the relevant residence time range of $(215 \mathrm{~ms}-315 \mathrm{~ms})$. As soon as the temperature is raised to $1220 \mathrm{~K}$, nucleation and surface growth rates become markedly pronounced. Further increasing the temperature does not bring about drastic variation in their individual strengths. It can be seen that in the present 
temperature range, soot formation rates (as a function of temperature) reach a saturation point after an initial boost. This hints at the plausible existence of a critical temperature (for the residence times considered) below which residence time dependency of soot inception and growth processes is not significant. Above this critical temperature, residence time dependency of soot particle size distribution increases, becoming more prominent at higher temperatures. Moreover, above a critical temperature, (here $1220 \mathrm{~K}$ ) soot formation processes (for a given residence time) have similar rates, and temperature dependence is not as severe as the residence times.

\subsubsection{Absolute Particle Size Distributions for Baseline Ethylene Pyrolysis}

In order to recognize the effect of acetylene as a principal soot precursor and soot growth species, it is requisite to compare pyrolysis cases of baseline ethylene with those reported above. The experimental conditions for baseline ethylene pyrolysis are summarized in Table 4.4 . All cases involve $4 \%$ ethylene pyrolysis. From here on, baseline ethylene case will be referred to as case 2, and acetylenedoped ethylene will be referred to as case 1 .

Figure 4.8 and Figure 4.9 show the comparison of soot particle size distributions obtained from baseline ethylene pyrolysis with that of acetylene doped ethylene pyrolysis. These figures clearly demonstrate the effect of acetylene on soot formation pathways. The soot particle size distributions for case 1 are considerably enhanced as compared to the soot PSDs for case 2, regardless of the experimental conditions. Particularly, case 2 has much narrower PSDs for all conditions, with mean diameters in the range of $5-6 \mathrm{~nm}$, suggesting that the detected particles are newly nucleated soot. Hence, soot surface growth seems inactive for baseline ethylene cases, whereas there is clear evidence of active soot growth for case 1, as illustrated by the widening of soot PSDs. The higher soot number densities and larger mean diameters (Table 4.5 indicate that acetylene strengthens soot nucleation and soot growth. As shown in Table 4.5, both total soot volume fractions and number densities increase significantly due to acetylene doping. However, soot volume fraction increase is greater than soot number density increase (soot volume fraction increase is almost 2.3 times more than soot number density increase). This shows that, besides soot inception, soot surface growth mechanisms are also intensified as a consequence of acetylene doping.

Interestingly, a closer look at the variation in soot properties for both cases (as a function of temperature and residence times) shows that soot number densities for case 1 are approximately 29 times higher than case 2, while total volume fractions are around 65 times higher for case 1 . The similarity in these numbers irrespective of experimental conditions may be attributed to the increased decomposition kinetics of ethylene itself, leading to substantial acetylene formation for both cases.

Table 4.4: Experimental Conditions for Pure 4\% Ethylene Pyrolysis

\begin{tabular}{|c|c|}
\hline Temperatures & Residence Times \\
\hline \multirow{2}{*}{$1220 \mathrm{~K}$} & $280 \mathrm{~ms}$ \\
& $315 \mathrm{~ms}$ \\
\hline $1230 \mathrm{~K}$ & $280 \mathrm{~ms}$ \\
\hline
\end{tabular}




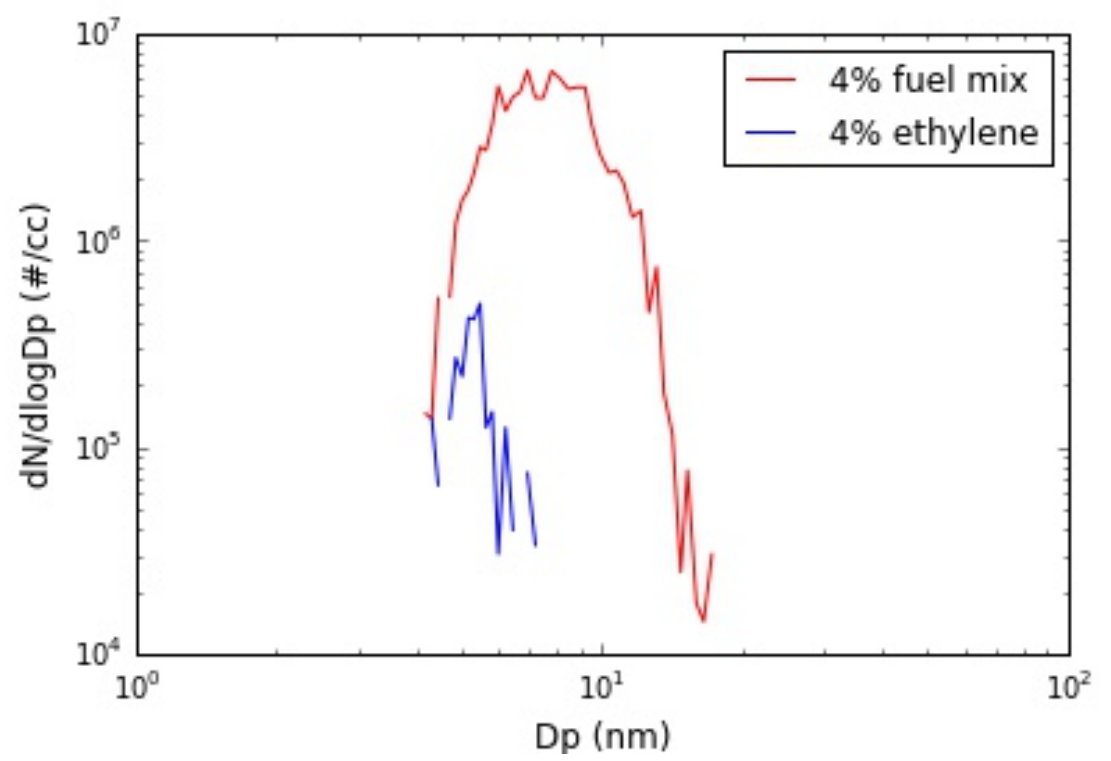

(a) $\mathrm{T}=1220 \mathrm{~K}$ and $280 \mathrm{~ms}$

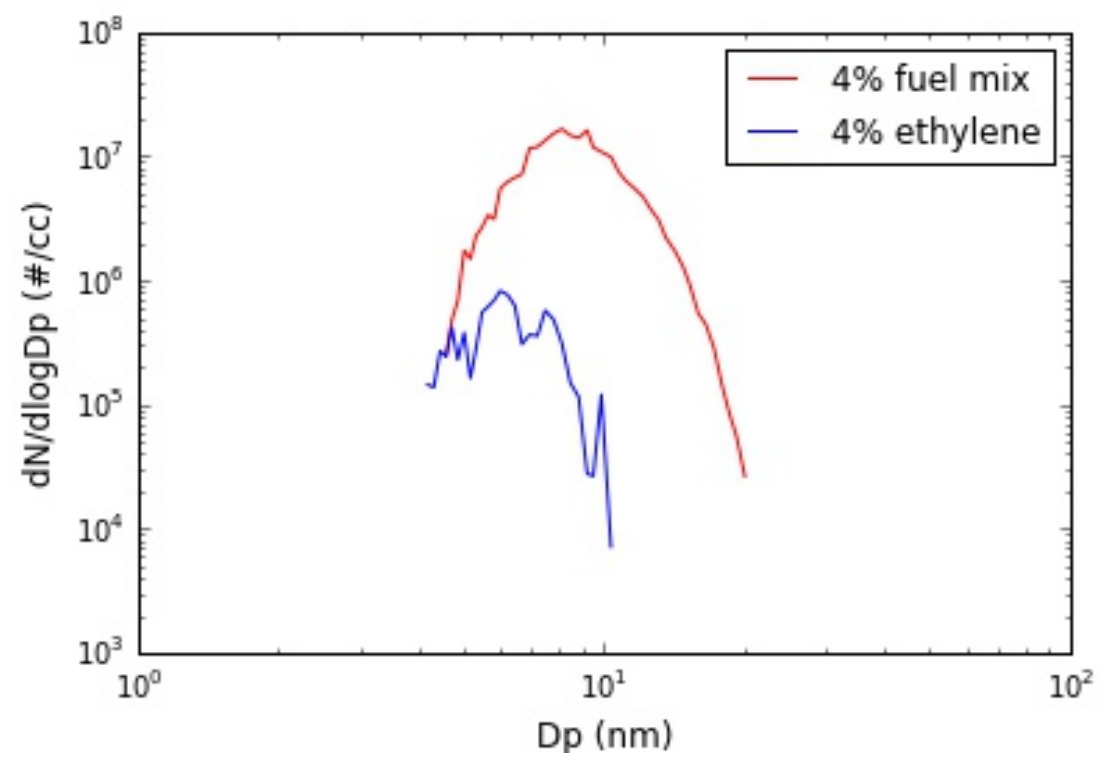

(b) $\mathrm{T}=1220 \mathrm{~K}$ and $315 \mathrm{~ms}$

Figure 4.8: Comparison of Absolute PSD of Baseline $\mathrm{C}_{2} \mathrm{H}_{4}$ with Absolute PSD of $\mathrm{C}_{2} \mathrm{H}_{2}$ - doped $\mathrm{C}_{2} \mathrm{H}_{4}$ (referred to as fuel mix) at $\mathrm{T}=1220 \mathrm{~K}$ 
Table 4.5: Comparison of Soot PSD Properties

\begin{tabular}{|c|c|c|}
\hline Soot PSD properties & $4 \%$ Fuel mix & $4 \%$ Ethylene (Baseline Case) \\
\hline Number Density $(\# / c c)$ & $1.38 \mathrm{E}+08$ & $4.88 \mathrm{E}+06$ \\
\hline Volume Fraction $(\mathrm{cc} / \mathrm{cc})$ & $7.9 \mathrm{E}-05$ & $1.25 \mathrm{E}-06$ \\
\hline Mean Diameter $(\mathrm{nm})$ & 7.95 & 6.07 \\
\hline
\end{tabular}

(a) $1230 \mathrm{~K}$ and $280 \mathrm{~ms}$

\begin{tabular}{|c|c|c|}
\hline Soot PSD properties & $4 \%$ Fuel mix & $4 \%$ Ethylene (Baseline Case) \\
\hline Number Density $(\# / \mathrm{cc})$ & $7.20 \mathrm{E}+07$ & $2.37 \mathrm{E}+06$ \\
\hline Volume Fraction $(\mathrm{cc} / \mathrm{cc})$ & $3.80 \mathrm{E}-05$ & $6.14 \mathrm{E}-07$ \\
\hline Mean Diameter $(\mathrm{nm})$ & 7.4 & 5.32 \\
\hline
\end{tabular}

(b) $1220 \mathrm{~K}$ and $280 \mathrm{~ms}$

\begin{tabular}{|c|c|c|}
\hline Soot PSD properties & $4 \%$ Fuel mix & $4 \%$ Ethylene (Baseline Case) \\
\hline Number Density $(\# / c c)$ & $2.84 \mathrm{E}+08$ & $9.30 \mathrm{E}+06$ \\
\hline Volume Fraction $(c c / c c)$ & $1.97 \mathrm{E}-04$ & $2.90 \mathrm{E}-06$ \\
\hline Mean Diameter $(\mathrm{nm})$ & 7.85 & 5.77 \\
\hline
\end{tabular}

(c) $1220 \mathrm{~K}$ and $315 \mathrm{~ms}$

Hence, the sooting tendencies of baseline ethylene and acetylene-doped ethylene increase by nearly the same amounts. In fact, the quantitative change in soot properties, as a function of temperature and residence time is comparable for both the acetylene-doped ethylene cases and the baseline ethylene case. This suggests that the impact of increasing temperature and residence times, as see in the previous section, was because of its direct influence on deposition kinetics of ethylene in the fuel mix.

The above discussion demonstratively proves the importance of acetylene in both soot nucleation and soot surface growth. Only a small amount of acetylene doping (14\% of fuel mixture) has a profound effect on soot particle size distributions. The HACA mechanism is well recognized as the dominant soot growth pathway. The results reported in this study not only validate hypothesis that HACA mechanism is the dominant soot growth pathway, they also show the role of acetylene as an important soot precursor. It is essential to note the persistent unimodal nature of the particle size distributions reported here. As mentioned before, this may be a manifestation of the parabolic velocity profile of the reactants owing to laminar flow. Another possible explanation for the unimodality may be the lack of competition between soot nucleation and soot coagulation.

\subsection{Error Analysis}

The present experimental methods of soot generation and measurement are associated with a few sources of uncertainties. In this study, soot is generated in a laminar MFTR. Laminar flow is characterized by parabolic velocity distribution. The residence time calculations are based on the average velocity, which is a simplification because the parabolic velocity distribution results in a residence time distribution. Existence of a residence time distribution causes different soot nucleation/growth rates along the radial direction inside the reactor. Additional sources of uncertainties in the measurement of experimental parameters are flow meters (1\%), differential pressure gauge for monitoring 


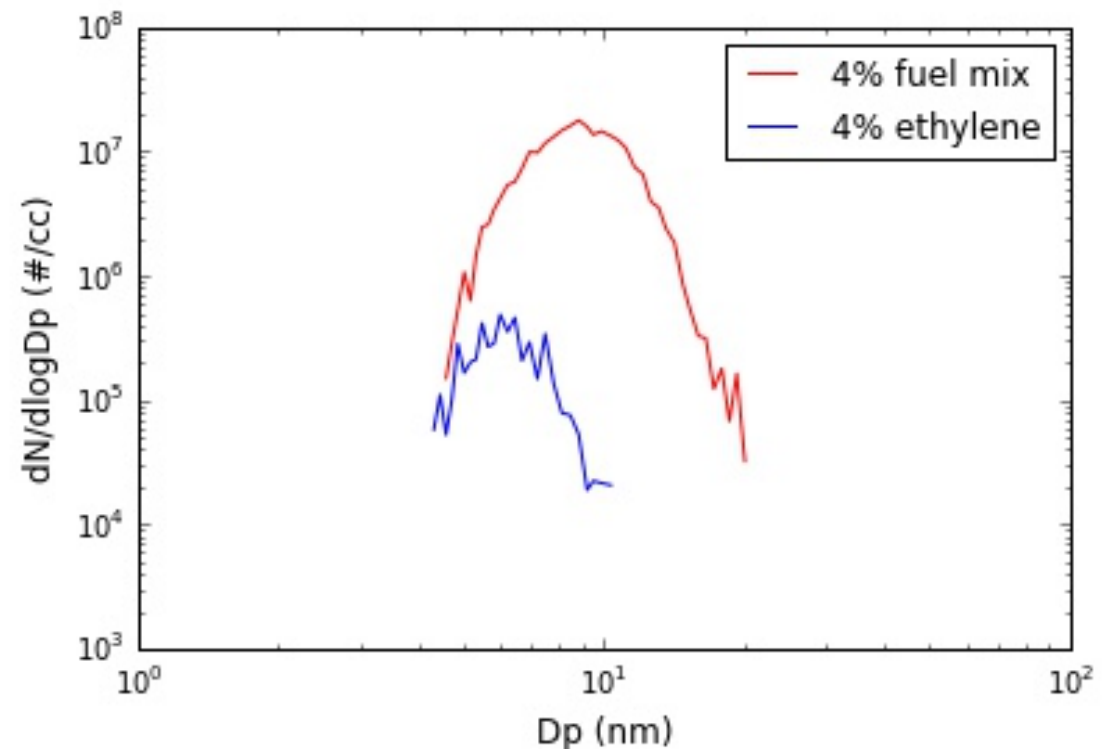

Figure 4.9: Comparison of Absolute PSD of Baseline $\mathrm{C}_{2} \mathrm{H}_{4}$ with Absolute PSD of $\mathrm{C}_{2} \mathrm{H}_{2}$ - doped $\mathrm{C}_{2} \mathrm{H}_{4}$ (referred to as fuel mix) at $\mathrm{T}=1230 \mathrm{~K}$ and $280 \mathrm{~ms}$

reaction pressure $(0.25 \%)$ and thermocouples $(0.75 \%)$. These uncertainties affect the accuracy of experimental parameters like reaction temperature, residence times and reaction pressure. The flow meter accuracy also affects the measured dilution ratio, which in turn affects the number densities. Soot sampling itself is associated with uncertainties due to the very small size of the sampling orifice with respect to the reactor diameter, which may result in loss of soot particles as they enter the sampling probe. Hence it is difficult to verify if the soot sample (measured by the SMPS) is a true representation of all the sizes formed inside the flow reactor. Besides this, other sources of uncertainties with regards to soot size measurements include the fluctuations in the readings of pressure gauge to measure the suction pressure across the orifice $\left(0.04\right.$ in $\mathrm{H}_{2} \mathrm{O}$ ), uncertainty in n-DMA ( $1 \%$ for sizes of $60 \mathrm{~nm}$ and $100 \mathrm{~nm}$ [103]), uncertainty in n-CPC (varies from $100 \%$ for $D_{p}$ of $2 \mathrm{~nm}$ to almost $0 \%$ for $D_{p}$ of $3 \mathrm{~nm}$ Figure 4.11, [7]). In the present experimental cases, mobility $D_{p}$ of soot particles was always greater than $3 \mathrm{~nm}$.

The major uncertainty in the measured soot number density arises from flow-meters and pressure gauge as these readings are used to calculate the dilution ratio. Three sets of data for each case (high pressure ethylene pyrolysis and atmospheric pressure acetylene-doped ethylene pyrolysis) were used to calculate standard deviation from the mean values of number density at each particle size to estimate the repeatability uncertainty. Figure 4.10 presents the soot particle size distributions with uncertainty bars for both high pressure cases and atmospheric pressure case. The uncertainty for high pressure ethylene pyrolysis $(2.7 \mathrm{~atm}, 1200 \mathrm{~K}$ ) (Figure 4.10b case is relatively higher than that for atmospheric pyrolysis of acetylene doped ethylene (1230 K and $280 \mathrm{~ms}$ ) (Figure 4.10a). This is because soot sampling at high pressure reaction conditions are done at relatively low suction pressure across the probe orifice, which results in high uncertainty in the pressure gauge readings 


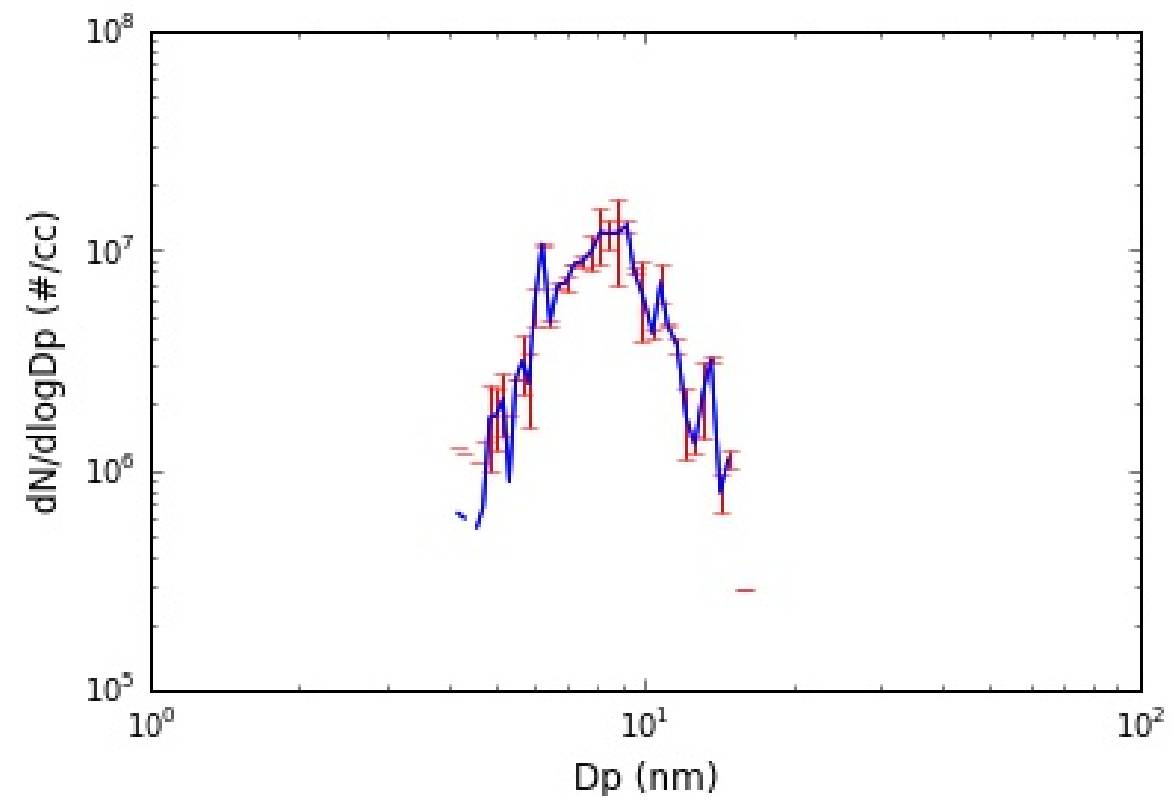

(a) Absolute Soot PSD for Atmospheric Pressure Pyrolysis of $C_{2} H_{2}$ doped $C_{2} H_{4}$ at $T=1230 \mathrm{~K}$ and $280 \mathrm{~ms}$

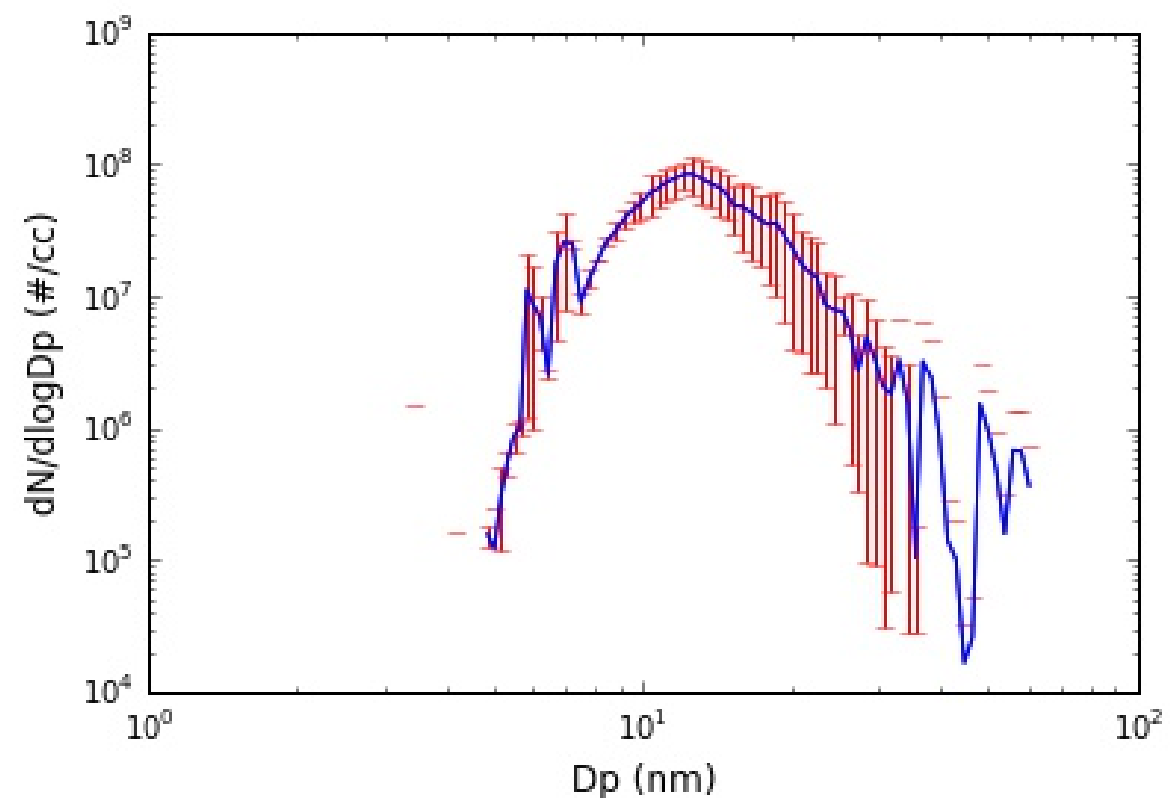

(b) Absolute Soot PSD for High Pressure Ethylene Pyrolysis: At $2.7 \mathrm{~atm}, \mathrm{~T}=1200 \mathrm{~K}$ and $240 \mathrm{~ms}$

Figure 4.10: Soot Particle Size Distribution with Error Bars

due to large fluctuations. 


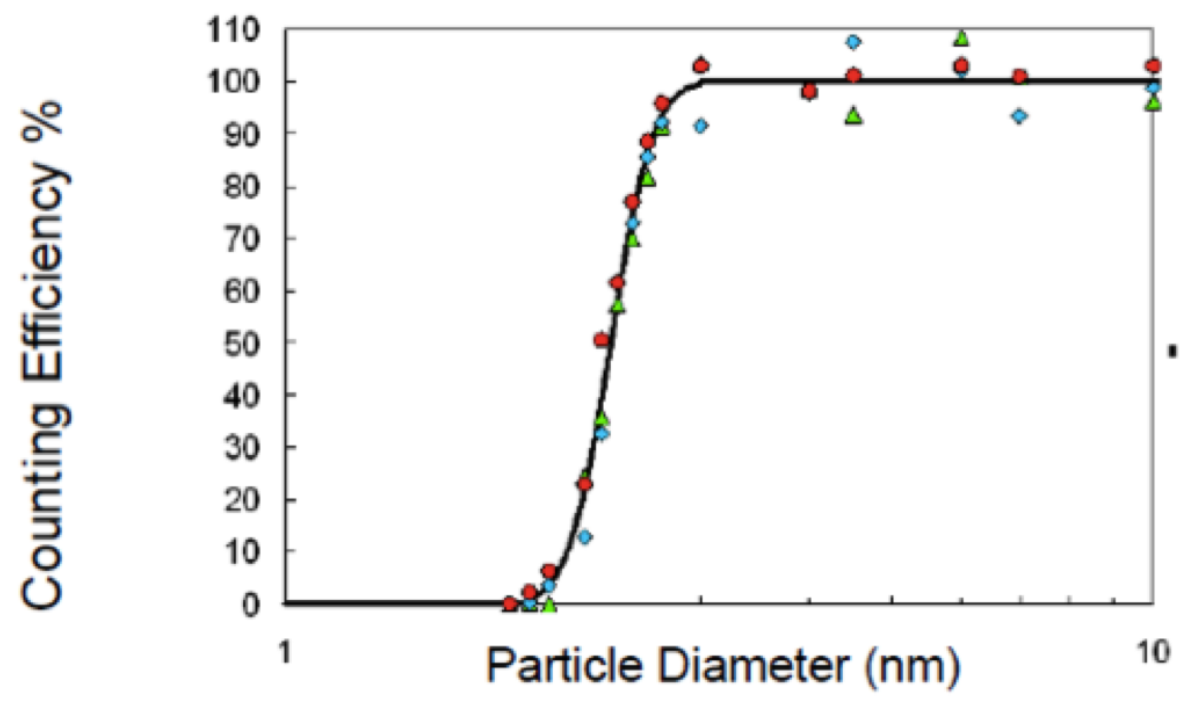

Figure 4.11: CPC counting efficiency curve [7]

\subsection{Summary}

This study was comprised of two major parts. The first part attempted to identify the effect of elevated pressures on sooting tendency of ethylene under pyrolytic conditions at $1200 \mathrm{~K}$. Although the pressure range considered was small, yet, this study succeeded in providing important insight into the trend of soot formation under elevated conditions. As expected, soot inception increased due to ethylene pyrolysis at high pressure. The increase in the number of newly nucleated soot particles caused an increase in soot mean diameter. A comparison of the soot number densities and volume fractions suggested that soot growth processes were not greatly impacted by change in pressure.

The second part of this study was aimed at identifying the importance of acetylene in soot formation processes, and validating the relevance of HACA mechanism in soot growth 63. Soot formation during the pyrolysis of acetylene ( $14 \%$ of total fuel mix) doped ethylene was monitored by tracking the evolution of particle size distribution under different temperatures and residence times. The results showed that doping ethylene with small amount of acetylene had a significant impact on soot nucleation and soot surface growth processes, as confirmed by the comparison of soot number densities and total volume fraction for acetylene-doped ethylene pyrolysis cases with baseline ethylene pyrolysis cases. It was clearly demonstrated that acetylene is an important soot precursor. Additionally, the results confirmed that HACA mechanism is indeed a dominant soot growth pathway. The results also showed that increasing the residence times increased soot formation processes (both nucleation \& surface growth), and the residence time dependency became more prominent at higher temperatures.

An important characteristic of soot obtained from fuel combustion in flow reactors is the unimodal nature of the particle size distribution. This was reported in a previous study [6], and was the observed trend in this study as well. As discussed before, this may be a direct consequence of 
the parabolic velocity profile inside the reactor causing residence time distribution. However, the unimodal size distribution could be due to lack of competition between soot nucleation and growth processes, which is the underlying reason for the bimodal nature of soot PSDs obtained from burner stabilized flames. 


\section{Chapter 5}

\section{Conclusion}

In this study, microflow tube reactors were used for fuel pyrolysis and soot generation. Soot so produced was sampled using a previously established and validated sampling technique [6], and the soot particle size distribution was subsequently measured in a high resolution SMPS. The study was conducted in two parts.

The first part of this study involved pyrolysis of $2 \%$ ethylene (in $98 \% \mathrm{~N}_{2}$ bath) at $1200 \mathrm{~K}$ and $240 \mathrm{~ms}$ residence time, over a varied range of reaction pressures $(2.5 \mathrm{~atm}-2.8 \mathrm{~atm})$. For this purpose, a micro-flow straight tubular reactor with an orifice at the reactor end was used. These experiments were successful in providing valuable insight about the effect of pressure on soot formation processes. Increase in pressure from $2.5 \mathrm{~atm}$ to $2.8 \mathrm{~atm}$ resulted in an increase in soot number densities by a factor of 100 , while the mean particle diameter increased from $8.47 \mathrm{~nm}$ to $11.7 \mathrm{~nm}$. Soot nucleation kinetics was found to be very sensitive to small variations in pressure. The increase in soot particle size was attributed to the large number of newly nucleated soot particles.

The second part of this study investigated soot particle size distributions during the pyrolysis of acetylene-doped ethylene ( $4 \%$ fuel mix, $96 \%$ diluent $N_{2}$ ) in a microflow straight tube reactor for varied residence times $(215 \mathrm{~ms}-315 \mathrm{~ms})$ over a range of temperatures $(1210 \mathrm{~K}-1230 \mathrm{~K})$. The soot PSDs for $1220 \mathrm{~K}$ and $1230 \mathrm{~K}$ were compared with those of baseline ethylene ( $4 \%$ ethylene, $96 \%$ diluent $N_{2}$ ) pyrolysis cases. The soot number densities increased by an order of magnitude for acetylenedoped ethylene pyrolysis case, while the soot mean diameter increased approximately by a factor of 1.35 (for $280 \mathrm{~ms}$ residence time). For both baseline ethylene pyrolysis case, and acetylene-doped ethylene pyrolysis case, residence time dependency of soot formation was revealed as well. The principal contribution of this set of experiments was to demonstratively validate the importance of acetylene in soot inception, and the role of HACA mechanism as a dominant soot growth pathway.

\section{$5.1 \quad$ Future Work}

Soot formation is a complex process with several steps that still lack complete understanding. Additionally, soot formation is dependent on several parameters. This study involved testing the effect 
of some of these parameters (temperature, pressure and residence time) and also examined the relevance of the theory that acetylene plays a crucial role as a soot precursor and soot growth species. However, there remains a need for more complete analysis of the above aspects of soot formation. Hence, going forward, the following investigations will be undertaken-

1. Repeat the experiments reported in this study in a novel microflow tubular reactor [6] with preheat helical section for heating diluent $N_{2}$ flow and sidearms (after the helical section) to introduce fuel. This design allows efficient heat transfer, assures well defined isothermal section and hence allows a more accurate calculation of residence time.

2. Experimental analysis of soot formation over a wider range of elevated pressure to gain fuller understanding about the soot inception/growth dynamics and its dependence on pressure.

3. Experimental investigation of soot properties formed at elevated pressure in turbulent flames using Laser induced incandescence as the diagnostic tool.

4. Chemical characterization of heavier polyaromatic hydrocarbons (PAHs) during early stages of soot formation in order to test the suggested importance of pyrene as the first building block of soot.

5. Although acetylene is acknowledged widely as the key species contributing to soot surface growth via the HACA mechanism, stable PAHs have received considerable attention as probable species causing soot growth by surface reaction (through radical sites on soot surface) [12. Hence, it is important to test this hypothesis in a similar manner as the experimental tests employed in this study for validating the importance of acetylene. 


\section{Bibliography}

[1] Henning Bockhorn. A short introduction to the problem - structure of the following parts. In Soot Formation in Combustion, pages 3-7. Springer, 1994.

[2] William C Hinds. Aerosol technology: properties, behavior, and measurement of airborne particles. John Wiley \& Sons, 2012.

[3] Operation and service manual for Electrostatic Classifiers, Series 3080. TSI, 2009.

[4] Operation and service manual for Nano water-based condensation particle counter, Series 3788. TSI, 2009.

[5] Zhigang Li and Hai Wang. Drag force, diffusion coefficient, and electric mobility of small particles. ii. application. Physical Review E, 68(6):061207, 2003.

[6] Rohit Singhal. Soot particle size distribution of a microflow tube reactor : Experimental and sectional modeling investigations. Master's thesis, University of Virginia, 2015.

[7] K Erickson, M Singh, and B Osmondson. Measuring nanoparticle size distributions in realtime: Key factors for accuracy. une, 13:15, 2016.

[8] Ian M Kennedy. The health effects of combustion-generated aerosols. Proceedings of the Combustion Institute, 31(2):2757-2770, 2007.

[9] David B Kittelson. Engines and nanoparticles: a review. Journal of aerosol science, 29(5):575$588,1998$.

[10] WH Su, QP Zhang, WZ Song, C Luo, and YF Siu. Problems of soot pollution and environmental effects in northern china. Aerosol science and technology, 10(2):231-235, 1989.

[11] Jörg Appel, Henning Bockhorn, and Michael Frenklach. Kinetic modeling of soot formation with detailed chemistry and physics: laminar premixed flames of c 2 hydrocarbons. Combustion and Flame, 121(1):122-136, 2000.

[12] Henning Richter and Jack B Howard. Formation of polycyclic aromatic hydrocarbons and their growth to soot - a review of chemical reaction pathways. Progress in Energy and Combustion science, 26(4):565-608, 2000. 
[13] Q Zhang, Hongsheng Guo, Fengshan Liu, GJ Smallwood, and MJ Thomson. Modeling of soot aggregate formation and size distribution in a laminar ethylene/air coflow diffusion flame with detailed pah chemistry and an advanced sectional aerosol dynamics model. Proceedings of the Combustion Institute, 32(1):761-768, 2009.

[14] RJ Santoro, HG Semerjian, and RA Dobbins. Soot particle measurements in diffusion flames. Combustion and Flame, 51:203-218, 1983.

[15] Fengshan Liu, Hongsheng Guo, Gregory J Smallwood, and Ömer L Gülder. Effects of gas and soot radiation on soot formation in a coflow laminar ethylene diffusion flame. Journal of Quantitative Spectroscopy and Radiative Transfer, 73(2):409-421, 2002.

[16] JB Moss, CD Stewart, and KJ Young. Modeling soot formation and burnout in a high temperature laminar diffusion flame burning under oxygen-enriched conditions. Combustion and Flame, 101(4):491-500, 1995.

[17] Ralf Starke and Paul Roth. Soot particle sizing by lii during shock tubepyrolysis of c $6 \mathrm{~h} 6$. Combustion and flame, 127(4):2278-2285, 2001.

[18] RD Kern and K Xie. Shock tube studies of gas phase reactions preceding the soot formation process. Progress in energy and combustion science, 17(3):191-210, 1991.

[19] Irvin Glassman. Soot formation in combustion processes. In Symposium (international) on combustion, volume 22, pages 295-311. Elsevier, 1989.

[20] BS Haynes, H Jander, and H Gg Wagner. Optical studies of soot-formation processes in premixed flames. Berichte der Bunsengesellschaft für physikalische Chemie, 84(6):585-592, 1980.

[21] Ahmet E Karataş and Ömer L Gülder. Soot formation in high pressure laminar diffusion flames. Progress in Energy and Combustion Science, 38(6):818-845, 2012.

[22] Martin Skov Skjøth-Rasmussen, Peter Glarborg, M Østberg, JT Johannessen, Hans Livbjerg, AD Jensen, and TS Christensen. Formation of polycyclic aromatic hydrocarbons and soot in fuel-rich oxidation of methane in a laminar flow reactor. Combustion and Flame, 136(1):91$128,2004$.

[23] Claudia Esarte, Ángela Millera, Rafael Bilbao, and María U Alzueta. Gas and soot products formed in the pyrolysis of acetylene-ethanol blends under flow reactor conditions. Fuel Processing Technology, 90(4):496-503, 2009.

[24] JD Bittner and JB Howard. Composition profiles and reaction mechanisms in a near-sooting premixed benzene/oxygen/argon flame. In Symposium (International) on Combustion, volume 18, pages 1105-1116. Elsevier, 1981.

[25] P Minutolo, G Gambi, A D'Alessio, and S Carlucci. Spectroscopic characterisation of carbonaceous nanoparticles in premixed flames. Atmospheric Environment, 33(17):2725-2732, 1999. 
[26] Nils Hansen, Terrill A Cool, Phillip R Westmoreland, and Katharina Kohse-Höinghaus. Recent contributions of flame-sampling molecular-beam mass spectrometry to a fundamental understanding of combustion chemistry. Progress in Energy and Combustion Science, 35(2):168-191, 2009 .

[27] Stefan Will, Stephan Schraml, Katharina Bader, and Alfred Leipertz. Performance characteristics of soot primary particle size measurements by time-resolved laser-induced incandescence. Applied optics, 37(24):5647-5658, 1998.

[28] RL Vander Wal and KJ Weiland. Laser-induced incandescence: development and characterization towards a measurement of soot-volume fraction. Applied Physics B, 59(4):445-452, 1994.

[29] Boman Axelsson, Robert Collin, and Per-Erik Bengtsson. Laser-induced incandescence for soot particle size measurements in premixed flat flames. Applied optics, 39(21):3683-3690, 2000 .

[30] T Ni, JA Pinson, S Gupta, and RJ Santoro. Two-dimensional imaging of soot volume fraction by the use of laser-induced incandescence. Applied Optics, 34(30):7083-7091, 1995.

[31] Pascale Desgroux, Xavier Mercier, and Kevin A Thomson. Study of the formation of soot and its precursors in flames using optical diagnostics. Proceedings of the Combustion Institute, 34(1):1713-1738, 2013.

[32] Kyeong-Ook Lee, Constantine M Megaridis, Serguei Zelepouga, Alexei V Saveliev, Lawrence A Kennedy, Olivier Charon, and Fouad Ammouri. Soot formation effects of oxygen concentration in the oxidizer stream of laminar coannular nonpremixed methane/air flames. Combustion and Flame, 121(1):323-333, 2000.

[33] Ümit Özgür Köylü. Quantitative analysis of in situ optical diagnostics for inferring particle/aggregate parameters in flames: Implications for soot surface growth and total emissivity. Combustion and flame, 109(3):488-500, 1997.

[34] Randall L Vander Wal. A tem methodology for the study of soot particle structure. Combustion science and technology, 126(1-6):333-351, 1997.

[35] Bing Hu, Bo Yang, and Umit O Koylu. Soot measurements at the axis of an ethylene/air non-premixed turbulent jet flame. Combustion and flame, 134(1):93-106, 2003.

[36] RA Dobbins and CM Megaridis. Morphology of flame-generated soot as determined by thermophoretic sampling. Langmuir, 3(2):254-259, 1987.

[37] Aamir D Abid, Nicholas Heinz, Erik D Tolmachoff, Denis J Phares, Charles S Campbell, and Hai Wang. On evolution of particle size distribution functions of incipient soot in premixed ethylene-oxygen-argon flames. Combustion and Flame, 154(4):775-788, 2008. 
[38] Bin Zhao, Zhiwei Yang, Murray V Johnston, Hai Wang, Anthony S Wexler, Michael Balthasar, and Markus Kraft. Measurement and numerical simulation of soot particle size distribution functions in a laminar premixed ethylene-oxygen-argon flame. Combustion and Flame, 133(1):173-188, 2003.

[39] V Krüger, C Wahl, R Hadef, Klaus Peter Geigle, W Stricker, and M Aigner. Comparison of laser-induced incandescence method with scanning mobility particle sizer technique: the influence of probe sampling and laser heating on soot particle size distribution. Measurement Science and Technology, 16(7):1477, 2005.

[40] Aamir D Abid, Joaquin Camacho, David A Sheen, and Hai Wang. Quantitative measurement of soot particle size distribution in premixed flames-the burner-stabilized stagnation flame approach. Combustion and Flame, 156(10):1862-1870, 2009.

[41] M Matti Maricq, Stephen J Harris, and Joseph J Szente. Soot size distributions in rich premixed ethylene flames. Combustion and Flame, 132(3):328-342, 2003.

[42] Christopher B Stipe, Brian S Higgins, Donald Lucas, Catherine P Koshland, and Robert F Sawyer. Inverted co-flow diffusion flame for producing soot. Review of scientific instruments, 76(2):023908, 2005.

[43] JY Hwang and SH Chung. Growth of soot particles in counterflow diffusion flames of ethylene. Combustion and flame, 125(1):752-762, 2001.

[44] Samuel L Manzello, David B Lenhert, Ahmet Yozgatligil, Michael T Donovan, George W Mulholland, Michael R Zachariah, and Wing Tsang. Soot particle size distributions in a well-stirred reactor/plug flow reactor. Proceedings of the Combustion Institute, 31(1):675-683, 2007.

[45] David B Lenhert and Samuel L Manzello. Effects of benzene and naphthalene addition on soot inception in a well-stirred reactor/plug flow reactor. Proceedings of the Combustion Institute, 32(1):657-664, 2009.

[46] Hai Wang, Bin Zhao, Barbara Wyslouzil, and Kiril Streletzky. Small-angle neutron scattering of soot formed in laminar premixed ethylene flames. Proceedings of the Combustion Institute, 29(2):2749-2757, 2002.

[47] Artur Braun, Frank E Huggins, Sönke Seifert, Jan Ilavsky, Naresh Shah, Kerry E Kelly, Adel Sarofim, and Gerald P Huffman. Size-range analysis of diesel soot with ultra-small angle x-ray scattering. Combustion and Flame, 137(1):63-72, 2004.

[48] Bin Zhao, Kei Uchikawa, and Hai Wang. A comparative study of nanoparticles in premixed flames by scanning mobility particle sizer, small angle neutron scattering, and transmission electron microscopy. Proceedings of the Combustion Institute, 31(1):851-860, 2007.

[49] Berk Öktem, Michael P Tolocka, Bin Zhao, Hai Wang, and Murray V Johnston. Chemical species associated with the early stage of soot growth in a laminar premixed ethylene-oxygenargon flame. Combustion and Flame, 142(4):364-373, 2005. 
[50] Michael Frenklach, David W Clary, William C Gardiner, and Stephen E Stein. Detailed kinetic modeling of soot formation in shock-tube pyrolysis of acetylene. In Symposium (International) on Combustion, volume 20, pages 887-901. Elsevier, 1985.

[51] Ian M Kennedy, Clement Yam, Darrell C Rapp, and Robert J Santoro. Modeling and measurements of soot and species in a laminar diffusion flame. Combustion and Flame, 107(4):368-382, 1996.

[52] Michael Frenklach. On the driving force of pah production. In Symposium (International) on Combustion, volume 22, pages 1075-1082. Elsevier, 1989.

[53] Hai Wang and Michael Frenklach. A detailed kinetic modeling study of aromatics formation in laminar premixed acetylene and ethylene flames. Combustion and flame, 110(1):173-221, 1997.

[54] Michael Frenklach. Reaction mechanism of soot formation in flames. Physical Chemistry Chemical Physics, 4(11):2028-2037, 2002.

[55] AV Krestinin. Detailed modeling of soot formation in hydrocarbon pyrolysis. Combustion and Flame, 121(3):513-524, 2000.

[56] Hai Wang. Formation of nascent soot and other condensed-phase materials in flames. Proceedings of the Combustion Institute, 33(1):41-67, 2011.

[57] MD Smooke, MB Long, BC Connelly, MB Colket, and RJ Hall. Soot formation in laminar diffusion flames. Combustion and Flame, 143(4):613-628, 2005.

[58] Jennifer D Herdman and J Houston Miller. Intermolecular potential calculations for polynuclear aromatic hydrocarbon clusters. The Journal of Physical Chemistry A, 112(28):6249-6256, 2008 .

[59] Charles A Schuetz and Michael Frenklach. Nucleation of soot: Molecular dynamics simulations of pyrene dimerization. Proceedings of the Combustion Institute, 29(2):2307-2314, 2002.

[60] Hassan Sabbah, Ludovic Biennier, Stephen J Klippenstein, Ian R Sims, and Bertrand R Rowe. Exploring the role of pahs in the formation of soot: Pyrene dimerization. The Journal of Physical Chemistry Letters, 1(19):2962-2967, 2010.

[61] John Z Wen, MJ Thomson, SH Park, SN Rogak, and MF Lightstone. Study of soot growth in a plug flow reactor using a moving sectional model. Proceedings of the Combustion Institute, 30(1):1477-1484, 2005.

[62] CH Kim, AM El-Leathy, F Xu, and GM Faeth. Soot surface growth and oxidation in laminar diffusion flames at pressures of 0.1-1.0 atm. Combustion and Flame, 136(1):191-207, 2004.

[63] Dorian SN Parker, Ralf I Kaiser, Tyler P Troy, and Musahid Ahmed. Hydrogen abstraction/acetylene addition revealed. Angewandte Chemie International Edition, 53(30):7740$7744,2014$. 
[64] Kin M Leung, Rune P Lindstedt, and WP Jones. A simplified reaction mechanism for soot formation in nonpremixed flames. Combustion and flame, 87(3):289-305, 1991.

[65] Andrei Kazakov and Michael Frenklach. Dynamic modeling of soot particle coagulation and aggregation: Implementation with the method of moments and application to high-pressure laminar premixed flames. Combustion and Flame, 114(3):484-501, 1998.

[66] A D'alessio, A D'Anna, P Minutolo, LA Sgro, and A Violi. On the relevance of surface growth in soot formation in premixed flames. Proceedings of the Combustion Institute, 28(2):2547$2554,2000$.

[67] M Matti Maricq. A comparison of soot size and charge distributions from ethane, ethylene, acetylene, and benzene/ethylene premixed flames. Combustion and flame, 144(4):730-743, 2006.

[68] Bin Zhao, Zhiwei Yang, Zhigang Li, Murray V Johnston, and Hai Wang. Particle size distribution function of incipient soot in laminar premixed ethylene flames: effect of flame temperature. Proceedings of the Combustion Institute, 30(1):1441-1448, 2005.

[69] H Kellerer, A Müller, H-J Bauer, and S Wittig. Soot formation in a shock tube under elevated pressure conditions. Combustion science and technology, 113(1):67-80, 1996.

[70] Heidi Böhm, Helga Jander, and D Tanke. Pah growth and soot formation in the pyrolysis of acetylene and benzene at high temperatures and pressures: Modeling and experiment. In Symposium (International) on Combustion, volume 27, pages 1605-1612. Elsevier, 1998.

[71] Décio S Bento, Kevin A Thomson, and Ömer L Gülder. Soot formation and temperature field structure in laminar propane-air diffusion flames at elevated pressures. Combustion and Flame, 145(4):765-778, 2006.

[72] DX Du, H Wang, and CK Law. Soot formation in counterflow ethylene diffusion flames from 1 to 2.5 atmospheres. Combustion and flame, 113(1):264-270, 1998.

[73] M Bönig, Chr Feldermann, H Jander, B Lüers, G Rudolph, and H Gg Wagner. Soot formation in premixed c $2 \mathrm{~h} 4$ flat flames at elevated pressure. In Symposium (International) on Combustion, volume 23, pages 1581-1587. Elsevier, 1991.

[74] Owen I Smith. Fundamentals of soot formation in flames with application to diesel engine particulate emissions. Progress in Energy and Combustion Science, 7(4):275-291, 1981.

[75] H Böhm, D Hesse, H Jander, B Lüers, J Pietscher, HGG Wagner, and M Weiss. The influence of pressure and temperature on soot formation in premixed flames. In Symposium (International) on Combustion, volume 22, pages 403-411. Elsevier, 1989.

[76] LL McCrain and WL Roberts. Measurements of the soot volume field in laminar diffusion flames at elevated pressures. Combustion and Flame, 140(1):60-69, 2005. 
[77] Kevin A Thomson, Ömer L Gülder, Elizabeth J Weckman, Roydon A Fraser, Greg J Smallwood, and Dave R Snelling. Soot concentration and temperature measurements in co-annular, nonpremixed ch 4/air laminar flames at pressures up to 4 mpa. Combustion and Flame, 140(3):222-232, 2005.

[78] Robert J Santoro and Christopher R Shaddix. Laser-induced incandescence. Applied combustion diagnostics, pages 252-286, 2002.

[79] Max Hofmann, Wolfgang G Bessler, Christof Schulz, and Helga Jander. Laser-induced incandescence for soot diagnostics at high pressures. Applied optics, 42(12):2052-2062, 2003.

[80] AD Abid, ED Tolmachoff, DJ Phares, H Wang, Y Liu, and A Laskin. Size distribution and morphology of nascent soot in premixed ethylene flames with and without benzene doping. Proceedings of the Combustion Institute, 32(1):681-688, 2009.

[81] Sandeep Sharma, Michael R Harper, and William H Green. Modeling of 1, 3-hexadiene, 2, 4-hexadiene and 1, 4-hexadiene-doped methane flames: Flame modeling, benzene and styrene formation. Combustion and Flame, 157(7):1331-1345, 2010.

[82] Claudia Esarte, María Abián, Ángela Millera, Rafael Bilbao, and María U Alzueta. Gas and soot products formed in the pyrolysis of acetylene mixed with methanol, ethanol, isopropanol or n-butanol. Energy, 43(1):37-46, 2012.

[83] M Frenklach, T Yuan, and MK Ramachandra. Soot formation in binary hydrocarbon mixtures. Energy \&3 fuels, 2(4):462-480, 1988.

[84] Xiaoqing You, Fokion N Egolfopoulos, and Hai Wang. Detailed and simplified kinetic models of n-dodecane oxidation: The role of fuel cracking in aliphatic hydrocarbon combustion. Proceedings of the Combustion Institute, 32(1):403-410, 2009.

[85] M Kasper, K Siegmann, and K Sattler. Evaluation of an in situ sampling probe for its accuracy in determining particle size distributions from flames. Journal of aerosol science, 28(8):1569$1578,1997$.

[86] Virgil A Marple and Kenneth L Rubow. Aerodynamic particle size calibration of optical particle counters. Journal of Aerosol Science, 7(5):425-433, 1976.

[87] Michael D Allen and Otto G Raabe. Slip correction measurements of spherical solid aerosol particles in an improved millikan apparatus. Aerosol Science and Technology, 4(3):269-286, 1985 .

[88] Panich Intra and Nakorn Tippayawong. An overview of differential mobility analyzers for size classification of nanometer-sized aerosol particles. 2008.

[89] Constantinos Sioutas. Evaluation of the measurement performance of the scanning mobility particle sizer and aerodynamic particle sizer. Aerosol Science \&3 Technology, 30(1):84-92, 1999.

[90] Pramod Kulkarni, Paul A Baron, and Klaus Willeke. Aerosol measurement: principles, techniques, and applications. John Wiley \& Sons, 2011. 
[91] EO Knutson and KT Whitby. Aerosol classification by electric mobility: apparatus, theory, and applications. Journal of Aerosol Science, 6(6):443-451, 1975.

[92] Zhigang Li and Hai Wang. Drag force, diffusion coefficient, and electric mobility of small particles. i. theory applicable to the free-molecule regime. Physical Review E, 68(6):061206, 2003.

[93] John Roberson, Clayton Crowe, et al. Engineering fluid mechanics. Houghton Mifflin Company, 1985 .

[94] William L Luyben. Chemical reactor design and control. John Wiley \& Sons, 2007.

[95] Octave Levenspiel. Chemical reaction engineering. Industrial $\& 3$ engineering chemistry research, 38(11):4140-4143, 1999.

[96] Robert J Kee, Michael E Coltrin, and Peter Glarborg. Chemically reacting flow: theory and practice. John Wiley \& Sons, 2005.

[97] Ujuma Shrestha, GP Simms, CG Moniruzzaman, and HK Chelliah. High-pressure fuel pyrolysis investigation using a microflow tube reactor. In 53rd AIAA Aerospace Sciences Meeting, Orlando, FL, 2015.

[98] R Shankar Subramanian. Heat transfer to or from a fluid flowing through a tube. Convective Heat Transfer I-Flow Through Conduits, Clarkson University, http://web2. c larks on. edu/proje ct s/subramanian/ch302/notes/Convective* 20Heat* 2OTransfer, 201.

[99] John M Roscoe, Alain R Bossard, and Margaret H Back. A kinetic modeling study of ethylene pyrolysis. Canadian Journal of Chemistry, 78(1):16-25, 2000.

[100] Chiara Saggese, Nazly E Sánchez, Alessio Frassoldati, Alberto Cuoci, Tiziano Faravelli, María U Alzueta, and Eliseo Ranzi. Kinetic modeling study of polycyclic aromatic hydrocarbons and soot formation in acetylene pyrolysis. Energy \& Fuels, 28(2):1489-1501, 2014.

[101] MM Maricq. Size and charge of soot particles in rich premixed ethylene flames. Combustion and Flame, 137(3):340-350, 2004.

[102] Larry A Glasgow. Transport phenomena: an introduction to advanced topics. John Wiley \& Sons, 2010.

[103] George W Mulholland, Michelle K Donnelly, Charles R Hagwood, Scott R Kukuck, et al. Measurement of $100 \mathrm{~nm}$ and $60 \mathrm{~nm}$ particle standards by differential mobility analysis. Journal of Research of the National Institute of Standards and Technology, 111(4):257, 2006. 